\title{
The M06 suite of density functionals for main group thermochemistry, thermochemical kinetics, noncovalent interactions, excited states, and transition elements: two new functionals and systematic testing of four M06-class functionals and 12 other functionals
}

\author{
Yan Zhao • Donald G. Truhlar
}

Received: 9 December 2006 / Accepted: 12 February 2007 / Published online: 12 July 2007

(C) Springer-Verlag 2007

\begin{abstract}
We present two new hybrid meta exchangecorrelation functionals, called M06 and M06-2X. The M06 functional is parametrized including both transition metals and nonmetals, whereas the M06-2X functional is a highnonlocality functional with double the amount of nonlocal exchange (2X), and it is parametrized only for nonmetals. The functionals, along with the previously published M06-L local functional and the M06-HF full-Hartree-Fock functionals, constitute the M06 suite of complementary functionals. We assess these four functionals by comparing their performance to that of 12 other functionals and Hartree-Fock theory for 403 energetic data in 29 diverse databases, including ten databases for thermochemistry, four databases for kinetics, eight databases for noncovalent interactions, three databases for transition metal bonding, one database for metal atom excitation energies, and three databases for molecular excitation energies. We also illustrate the performance of these 17 methods for three databases containing 40 bond lengths and for databases containing 38 vibrational frequencies and 15 vibrational zero point energies. We recommend the M06$2 \mathrm{X}$ functional for applications involving main-group thermochemistry, kinetics, noncovalent interactions, and electronic excitation energies to valence and Rydberg states. We recommend the M06 functional for application in organometallic
\end{abstract}

Contribution to the Mark S. Gordon 65th Birthday Festschrift Issue.

Electronic supplementary material The online version of this article (doi:10.1007/s00214-007-0310-x) contains supplementary material, which is available to authorized users.

Y. Zhao · D. G. Truhlar $(\varangle)$

Department of Chemistry and Supercomputing Institute,

University of Minnesota, 207 Pleasant Street S.E.,

Minneapolis, MN 55455-0431, USA

e-mail: truhlar@umn.edu and inorganometallic chemistry and for noncovalent interactions.

Keywords Density functional theory - Exchange . Correlation · Metals · Organic molecules

\section{Introduction}

The continued development of improved exchangecorrelation functionals is essential for expanding the applicability of Kohn-Sham density functional theory (DFT). Over the past 5 years, much progress [1-19] has been made, primarily due to the exploitation of kinetic energy density $[1-6,10,12,14,16,19]$ and systematic optimization of exchange-correlation functionals against broad and diverse databases [4-6, 10-12,14,16-19].

In a recent review [20], Scuseria and Staroverov summarized the six strategies that have been widely employed for designing density functionals: (1) local spin density approximation (LSDA), (2) density-gradient expansion, (3) constraint satisfaction, (4) modeling the exchange-correlation hole, (5) empirical fits, and (6) mixing Hartree-Fock and approximate DFT exchange. Our M05 [12] and M05-2X [14] functionals were constructed with strategies (3), (5), and (6). Recently we developed a local functional M06-L [16], which is constructed via strategies (3), (4) and (5) and is based on the M05 [12] and VSXC [21] functional forms, and a fullHartree-Fock-exchange functional, M06-HF [19], which is constructed with strategies (3), (4), (5), and (6).

When Scuseria and Staroverov discussed constraint satisfaction [20], they were referring to constraints such as having the correct limit for a uniform electron gas. All the functionals we have designed recently $[4,6,10,12,14,16,19]$ satisfy this constraint. However, there are other kinds of constraints that one wishes to enforce sometimes, but not always. An 
example is constraining the functional to be local, where we use the word "local" in the sense as Becke [22], so that it includes spin density gradient and spin kinetic energy density (as well as local spin density) but excludes HartreeFock exchange. Although the exact density functional must be nonlocal [9], local functionals allow one to use density fitting algorithms [23-32] and plane wave algorithms [33] that require much less computation than the best algorithms for nonlocal functionals, and thus they are preferred for practical computations on large systems. Furthermore, local functionals allow calculations on periodic systems with small band gaps, for which nonlocal functionals are prohibitively expensive. Another optional constraint is full Hartree-Fock exchange. Only functionals with full Hartree-Fock exchange are satisfactory for one-electron systems [9] and long-range charge-transfer excited states [19,34]. Enforcing locality or full Hartree-Fock exchange restricts the flexibility of a functional, and therefore it limits the accuracy that can be achieved for some applications.

An ideal functional would be well suited to all applications in chemistry and physics. However, although considerable progress has been made $[12,13,15,18]$, such functionals are unknown and are unlikely to be discovered in the foreseeable future. Therefore, in the design of functionals, we should have a goal or objective that specifies the area or areas of application for which it is designed. Within those areas, one seeks the broadest possible accuracy. In our work, we have focused on five broad areas, which we will refer to as follows:

\section{TC main-group thermochemistry \\ $\mathrm{BH}$ barrier heights \\ NC noncovalent interactions \\ ES electronic spectroscopy (sometimes called "UV-vis" spectroscopy)}

TM transition metal bonding

Functionals designed for the TC area should predict accurate structures, energies, and vibrational frequencies for compounds containing only main-group elements. Functionals designed for the $\mathrm{BH}$ area should predict accurate structures, energies, and vibrational frequencies of transition states. Functionals designed for the NC area should predict accurate structures, energies, and vibrational frequencies of complexes held together by noncovalent forces and would also be expected to be particularly useful for soft materials and solvation. Functionals designed for the ES area should predict accurate structures, energies, and vibrational frequencies of systems in electronically excited states; if a functional does not have full Hartree-Fock exchange though, one might look only at valence and Rydberg states, not charge transfer excited states. Functionals designed for the TM area should predict accurate structures, energies, and vibrational frequencies for compounds containing transition metals. Functionals can be developed to perform well in one or more of these five niches, with or without the local or full-Hartree-Fock constraint of the previous paragraph. As one studies functionals designed for a particular niche, one may discover correlations between niches and subniches. For example, a functional designed for the TM area may also be well suited to that subset of the MG area involving systems with high multireferecne character. We also found that functionals that give good performance for the $\mathrm{NC}$ and $\mathrm{BH}$ areas are good for certain thermochemical properties that are sensitive to medium-range correlation energy [35].

In designing functionals for each of these niches, one needs the broadest possible databases of accurate data (training and testing data) in each area. Although the development of such databases is subject to continual improvement (more accurate values, more diverse data within the designated area, and/or more properties, for example polariazabilities or dipole moments or barrier heights for transition metal reactions), we have made some progress in developing useful databases [4, 19,36-40]. The present article will use these databases plus some new ones to test a variety of functionals. We will average over databases in a given area to obtain an overall assessment of performance of the functionals in that area.We will then average the area averages over two or more areas to learn how well selected functionals can do on two or more areas. For example, can we find a functional that is good for both the TM and BH areas? The present article will consider this kind of question.

In a previous work, we have designed two very broadly accurate functionals without local or full-Hartree-Fock constraints. The first functional, called M05 [12], is designed to be as accurate as possible for the TM, MG, BH, and NC areas.The second one, called M05-2X [14], is designed only for main-group chemistry, in particular to be good for the $\mathrm{MG}, \mathrm{BH}$, and $\mathrm{NC}$ areas. As a side effect, this functional turns out to be excellent for non-charge-transfer states in electronic spectroscopy. We also designed two functionals with constraints. The first, called M06-L [16], is constrained to be local and is designed to be as good as possible, under that constraint, for the $\mathrm{TM}, \mathrm{MG}, \mathrm{BH}$, and $\mathrm{NC}$ areas. In the process of designing this functional, we improved the functional forms enough that it is actually better than M05 for the TM area, but because of its constraint, it is less adequate for the MG, BH, and NC areas. A fourth designer functional designed in a similar manner to the three just mentioned is called M06-HF and is constrained to have full Hartree-Fock exchange. Such a functional tends to be very bad for the TM area, so, as for M05-2X, we optimized this functional only for the $\mathrm{MG}, \mathrm{BH}$, and $\mathrm{NC}$ areas. It turns out, as expected, to be the only functional with useful accuracy for charge-transfer states in electronic spectroscopy. 
Based on what we learned in optimizing M06-L and M06HF we can return to the objectives we had for M05 and M05$2 \mathrm{X}$ and re-optimize functionals for those objectives with the new functional forms. These new functionals will be called M06 and M06-2X and they are presented here for the first time. Some practioners believe that one should not introduce new functionals very often. They believe that there are too many functionals and that we need to settle in with a few well-designed functionals (maybe even only one functional) and use them (or it) for a long time to develop confidence in their (or its) robustness. This is a legitimate approach, and readers with this attitude need not use the M06 and M062X functionals. We still believe that M05 and M05-2X are excellent functionals; in fact, by some criteria they are the very best available functionals at this time (except for M06 and M06-2X), and we encourage readers to use these functionals for their applications - they have already been quite successful and shown good robustness [14,16, 19,35,40-48]. Other readers, though, are happy to have even better functionals designed with our improved functional forms; their work should benefit from the increased accuracy of the new functionals. These readers may wish to switch from M05 and M05-2X to M06 and M06-2X, respectively.

The paper is organized as follows. Section 2 presents our databases. Section 3 gives computational details. Section 4 discusses the theory and parametrization of the two new functionals. Section 5 alerts the reader where to look for explanations of acromyms. Section 6 is a brief classification of the density functionals considered in this article; this classification provides the keys to the underlying physics. Section 7 presents results and discussion for energetic quantities, including many energies not used in training; and Sect. 8 gives results and tests for bond lengths, vibrational frequencies, and zero point energies, none of which were used in training. Section 9 concludes the paper. The appendix contains a glossary.

\section{Databases}

As described in a previous paper [16], our general notation for databases is $\mathrm{YN} / \mathrm{V}$, where $\mathrm{Y}$ is an acronym for the type of data, $N$ is the number of data, and $\mathrm{V}$ is a version number (sometimes omitted if there has only been one version with the same YN). Since version numbers (when used) are specified in Table 1, we usually omit them in the text and in other tables.

In the present article we emphasize energetic databases. We have considered geometries $[4,6,16,37,42,44]$ and vibrational frequencies [16] in previous articles, and we generally have found that functionals that perform well for energies also perform well for geometries and frequencies, although the rank order may be different; we will illustrate this with
Table 1 Organization of energetic databases

\begin{tabular}{|c|c|}
\hline Databases & Refs. \\
\hline \multicolumn{2}{|l|}{ I. Main-group energetics (MG350) } \\
\hline \multicolumn{2}{|l|}{ A. Thermochemistry (TC177) } \\
\hline \multicolumn{2}{|l|}{ 1. Standard data (SD143) } \\
\hline a. Atomization energies (AE109/05) & [14] \\
\hline b. Ionization potentials (IP13/3) & {$[10,12,14,52]$} \\
\hline c. Electron affinities (EA13/3) & {$[10,12,14,52]$} \\
\hline d. Proton affinities of small molecules (PA8) & [40] \\
\hline 2. Alkyl bond dissociation energies (ABDE4/05) & {$[14,16,60]$} \\
\hline 3. $\pi$ system thermochemistry $(\pi \mathrm{TC} 13)$ & {$[14,16]$} \\
\hline a. $\pi$ system isomerization energies ( $\pi$ IE3) & {$[40,102]$} \\
\hline b. Proton affinities of conjugated polyenes (PA-P5) & [40] \\
\hline $\begin{array}{l}\text { c. Proton affinities of conjugated } \\
\text { Schiff bases (PA-SB5) }\end{array}$ & [40] \\
\hline 4. Hydrocarbon thermochemistry (HC7) & [35], present \\
\hline 5. Difficult cases (DC10) & Present \\
\hline \multicolumn{2}{|l|}{ B. Diverse barrier heights (DBH76) } \\
\hline 1. Heavy-atom transfer (HATBH12/05) & {$[50]$} \\
\hline 2. Nucleophilic substitution (NSBH16/05) & {$[50]$} \\
\hline 3. Unimolecular and association (UABH10/05) & [50] \\
\hline 4. Hydrogen transfer $(\mathrm{HTBH} 38 / 04)$ & {$[8,14,50]$} \\
\hline \multicolumn{2}{|l|}{ C. Noncovalent interaction energies (NCIE53) } \\
\hline \multicolumn{2}{|l|}{ 1. Noncovalent complexes (NCCE31/05) } \\
\hline a. Hydrogen bonding (HB6/04) & [37] \\
\hline b. Charge-transfer complexes (CT7/04) & [37] \\
\hline c. Dipole-interaction complexes (DI6/04) & [37] \\
\hline d. Weak interaction complexes (WI7/05) & {$[10]$} \\
\hline e. $\pi-\pi$ stacking (PPS5/05) & [10] \\
\hline $\begin{array}{l}\text { 2. Noncovalent interaction of biological } \\
\text { importance (S22) }\end{array}$ & {$[44,65]$} \\
\hline a. Hydrogen bonding (JHB7) & {$[44,65]$} \\
\hline b. Predominantly dispersion-like (JDL8) & {$[44,65]$} \\
\hline c. Mixed (JM7) & {$[44,65]$} \\
\hline D. Electronic spectroscopy (ES44) & [19] \\
\hline 1. Non-charge-transfer (VRE41) & [19] \\
\hline a. Valence excited states (VES21) & [19] \\
\hline b. Ryderberg excited states (RES20) & [19] \\
\hline 2. Charge transfer excited states (CTES3) & [19] \\
\hline \multicolumn{2}{|l|}{ II. Transition metal energetics (TME53) } \\
\hline \multicolumn{2}{|l|}{ A. Transition metal reaction energies (TMRE48) } \\
\hline \multicolumn{2}{|l|}{ 1. Transition metal atomization energies (TMAE9/05)[38] } \\
\hline 2. Metal ligand bond energies (MLBE21/05) & [39] \\
\hline $\begin{array}{l}\text { 3. } 3 d \text { transition metal reaction energies } \\
\text { ( } 3 d \text { TMRE18/06) }\end{array}$ & {$[43,76]$} \\
\hline B. Metal atom excitation energies (MAEE5) & [16] \\
\hline
\end{tabular}

selected tests for geometries and frequencies near the end of the article. The energetic databases we consider in the present article are organized in Table 1 . Since most of these databases 
are fully described elsewhere $[4,6,8,12,14,16,37,40,41,43$, $44,49,50]$ and are presented in Supporting Information, we will not review them in detail here, but each database will be described briefly when we use it to test the accuracy of density functionals.

We note here that all data in the energetic databases are zero-point-exclusive (e.g., dissociation energies are $D_{\mathrm{e}}$, not $D_{0}$ ). When data have been derived from experiments, this means that thermal vibrational-rotational energies and zero point vibrational energies have been removed. The values in the database are thus appropriate for direct comparison to Born-Oppenheimer electronic energies, including nuclear repulsion.

In addition to using some of the database developed for testing (given in Table 1), one additional database, called AE17, is used during parametrization. AE17 contains the total atomic energies [51] of the atoms from $\mathrm{H}$ to $\mathrm{Cl}$.

\section{Computational methods}

\subsection{Geometries and basis sets}

The choice of which basis set(s) to use in developing, testing, and validating density functionals is a difficult one. In this regard we received two kinds of comments by readers of our previous articles and a reviewer of this paper. One comment is that our basis sets are too small because it sometimes requires very large basis sets to achieve full convergence and to fully eliminate basis set superposition error. The other is that we should present more tests with small basis sets because "most computational chemists would like to apply the functionals to much larger systems" where basis sets as large as those used here "would be too costly." Our usual procedure has been to present results for partially augmented polarized double zeta basis sets ("double zeta quality") and partially augmented multiply polarized triple zeta basis sets ("triple zeta quality") with occasional use of quadruple zeta quality. In general, we have found that for organic molecules, a double zeta quality basis set is usually reasonable, and triple zeta quality is generally more quantitative. For system containing metals, double zeta quality is more useful but can be dangerous and checking basis set convergence for each kind of system is advisable. In the present article, to keep the paper from becoming unwieldy, we use only a single basis set for each case, but readers can refer to our previous papers $[6,14,37-39,50,52,53]$ for comparisons of basis sets. Of the basis sets employed here, as delineated below, MQZVP, QZVP, AVQZ and aug-cc-pVQZ are of quadruplezeta quality; MG3, MG3S, 6-311+G(2df,2p), the augmented Sadlej pVTZ basis, and TZQ are of triple-zeta quality; 6$311+\mathrm{G}(\mathrm{d}, \mathrm{p})$ is triple-zeta quality in the valence space with double-zeta-quality polarization functions, and $6-31+\mathrm{G}(\mathrm{d}, \mathrm{p})$ and 6-31G(d) are of double-zeta quality.
The calculated energies that we compare to the MGAE109, IP13, EA13, PA8, ABDE, HC7, $\pi$ TC13, and DC10 databases are single-point calculations. The geometries used for MGAE109, IP13, and EA13 were optimized by QCISD/MG3, where QCISD is quadratic configuration interaction with single and double excitations [54], and MG3 is the modified [55,56] G3Large [57] basis set. The MG3 basis set [55] is also called G3LargeMP2 [56], and it is the same as 6-311++G(3d2f, 2df, 2p) [58,59] for H-Si, but improved [57] for P-Ar. Geometries for the PA8 molecules were optimized at the MP2(full)/6-31G(2df,p) level of theory. Geometries [60] for the ABDE4 database are optimized with B3LYP and the 6-31G(d) basis set. MP2/6-311+G(d,p) geometries were employed for the HC7 and DC10 databases, and MP2/6$31+\mathrm{G}(\mathrm{d}, \mathrm{p})$ geometries were employed for $\pi \mathrm{TC} 13$.

The single-point energies were calculated with the MG3S [52] basis set for MGAE109, IP13, EA13, HC7, and $\pi$ TC13, with the $6-311+\mathrm{G}(2 \mathrm{df}, 2 \mathrm{p})$ basis set [59] for PA8, and with the 6-311+G(3df,2p) basis set [59] for ABDE4. The MG3S basis is like MG3 except that diffuse functions are removed on hydrogen. We also employed the MG3S basis set for the AE17 calculations.

A new basis set was designed and employed with MP2/6$311+G(d, p)$ geometries for the DC10 database of ten difficult cases for DFT. The new basis set is called MQZVP, and it is a modification of the quadruple-zeta-quality QZVP basis of Weigend et al. [61]. In the MQZVP basis set, we deleted $f$ basis functions for hydrogen, and we also deleted $g$ functions for $\mathrm{B}-\mathrm{Ne}$. We augmented the basis set for $\mathrm{H}$ with a diffuse $s$ function, and we augmented the basis sets for B-Ar with a diffuse $s$ function and a set of diffuse $p$ functions. The exponent of the diffuse $s$ function was taken as 0.2 times the most diffuse $s$ function already in the QZVP basis set, and the exponent for the diffuse $p$ functions was taken as 0.2 times the most diffuse $p$ exponent already in the QZVP basis.

For barrier heights we used QCISD/MG3 geometries $[50,52]$ and single-point energies were calculated with MG3S. Geometries for all molecules in the HB6, CT7, DI6, and WI7 noncovalent databases and the $\left(\mathrm{C}_{2} \mathrm{H}_{4}\right)_{2}$ and $\left(\mathrm{C}_{2} \mathrm{H}_{2}\right)_{2}$ dimers in the PPS5/05 database are optimized at the MC-QCISD/3 level, where MC-QCISD is the multi-coefficient QCISD method $[62,63]$. The geometries for the benzene dimers in the PPS5 database are taken from Sinnokrot and Sherrill [64]. The methods used to obtain geometries [65] for the S22 database are specified in elsewhere [65] and in Supporting Information. The MG3S basis set is employed for the NC31 databases, and the $6-31+\mathrm{G}(\mathrm{d}, \mathrm{p})$ basis is used for $\mathrm{S} 22$.

The time-dependent density functional theory (TDDFT) [34,66-71] calculations on the $\mathrm{CO}, \mathrm{N}_{2}$, and $\mathrm{HCHO}$ molecules employed the augmented Sadlej pVTZ basis set [72,73] and experimental geometries [74]. The $6-31+\mathrm{G}(\mathrm{d}, \mathrm{p})$ basis set was employed for the calculations on $\mathrm{NH}_{3} \cdots \mathrm{F}_{2}$. The 
geometry for the charge-transfer complex, $\mathrm{NH}_{3} \cdots \mathrm{F}_{2}$, was optimized at the MC-QCISD/3 level, and the intermolecular distance of the two monomers was changed to $6 \AA$, without reoptimization. The 6-31G(d) basis set was employed for the $\mathrm{C}_{2} \mathrm{H}_{4} \cdots \mathrm{C}_{2} \mathrm{~F}_{4}$ complex, and we used experimental geometries [75] for each monomer with the intermolecular distance being $8 \AA$. The geometry of tetracene was optimized at the B3LYP/6-31+G(d,p) level, and all TDDFT calculations for tetracene employed the 6-311G(2d,p) basis set.

Geometries for TMAE9 and MLBE21/05 are optimized consistently with each level of theory. We employed the TPSS/QZVP geometries [76] for 3dTMRE18. We used the TZQ basis [38] for TMAE9 and MLBE21 and the QZVP basis for 3dTMRE18.

We employed the aug-cc-pVQZ basis set for Be [77], $\mathrm{Mg}$ [77], and $\mathrm{Cu}^{+}$[78] in the MAEE5 database. The basis set for Mn is QZVP [61], and that for Pd is the AVQZ basis set from Quintal et al. [79].

Note that the MG3, MG3S, TZQ, and MQZVP basis sets can be obtained from our basis set web page [80].

\subsection{Relativistic effects}

Incorporation of relativistic effects in all calculations has been described in detail in a previous paper [16], and we briefly outline it here. Scalar relativistic effects are not included for main group elements in the present study. Scalar relativistic effects have been taken into account for transition metals using a relativistic effective core potential $[38,39]$, or a relativistic DFT [76] or HF calculation [81,82]. The vector relativistic effect is included by adding spin-orbit coupling. In all the calculations presented in this paper, the spinorbit stabilization energy was added to atoms and open shell molecules for which it is nonzero, as described previously $[38,39,55]$.

\subsection{Counterpoise correction}

For the noncovalent complexes in NCCE31 and S22, we performed calculations with and without the counterpoise corrections $[83,84]$ for basis set superposition error (BSSE).

\subsection{Software}

All calculations in this article were performed with a locally modified version of the GAUSSIAN03 program [85].

\section{Theory and parametrization}

The local parts of the M06 and M06-2X functionals depend on three variables: spin density $\left(\rho_{\sigma}\right)$, reduced spin density gradient $x_{\sigma}$, and spin kinetic energy density $\tau_{\sigma}$.

$$
\begin{aligned}
& x_{\sigma}=\frac{\left|\nabla \rho_{\sigma}\right|}{\rho_{\sigma}^{4 / 3}} \sigma=\alpha, \beta \\
& \tau_{\sigma}=\frac{1}{2} \sum_{i}^{\text {occup }}\left|\nabla \Psi_{i \sigma}\right|^{2}
\end{aligned}
$$

The M06 functional includes terms based on the VSXC functional, and these terms involve a working variable $z_{\sigma}$ and two working functions $\gamma$ and $h$ :

$$
\begin{aligned}
z_{\sigma}= & \frac{2 \tau_{\sigma}}{\rho_{\sigma}^{5 / 3}}-C_{F}, \quad C_{F}=\frac{3}{5}\left(6 \pi^{2}\right)^{2 / 3} \\
\gamma\left(x_{\sigma}, z_{\sigma}\right)= & 1+\alpha\left(x_{\sigma}^{2}+z_{\sigma}\right) \\
h\left(x_{\sigma}, z_{\sigma}\right)= & \left(\frac{d_{0}}{\gamma\left(x_{\sigma}, z_{\sigma}\right)}+\frac{d_{1} x_{\sigma}^{2}+d_{2} z_{\sigma}}{\gamma_{\sigma}^{2}\left(x_{\sigma}, z_{\sigma}\right)}\right. \\
& \left.+\frac{d_{3} x_{\sigma}^{4}+d_{4} x_{\sigma}^{2} z_{\sigma}+d_{5} z_{\sigma}^{2}}{\gamma_{\sigma}^{3}\left(x_{\sigma}, z_{\sigma}\right)}\right)
\end{aligned}
$$

Note that $\sigma$ denotes the component along an arbitrary spacefixed axis of electron spin angular momentum.

\subsection{Meta-generalized gradient approximation (GGA) exchange functional}

The M06 functional form is the same as the M06-L functional [16], which is a linear combination of the functional forms of the M05 $[12,14]$ and VSXC $[21,86]$ exchange functionals. In particular the M06 exchange functional is given by

$$
\begin{aligned}
E_{\mathrm{X}}^{\mathrm{M} 06}= & \sum_{\sigma} \int \mathrm{d} r\left[F_{\mathrm{X} \sigma}^{\mathrm{PBE}}\left(\rho_{\sigma}, \nabla \rho_{\sigma}\right) f\left(w_{\sigma}\right)\right. \\
& \left.+\varepsilon_{\mathrm{X} \sigma}^{\mathrm{LSDA}} h_{\mathrm{X}}\left(x_{\sigma}, z_{\sigma}\right)\right]
\end{aligned}
$$

where $h_{\mathrm{X}}\left(x_{\sigma}, z_{\sigma}\right)$ is defined in Eq. (5), $F_{\mathrm{X} \sigma}^{\mathrm{PBE}}\left(\rho_{\sigma}, \nabla \rho_{\sigma}\right)$ is the exchange energy density of the PBE [87] exchange model (which is itself a modified version of the B86 [88] exchange functional), $\varepsilon_{\mathrm{X} \sigma}^{\mathrm{LSDA}}$ is the local spin density approximation [89] for exchange

$\varepsilon_{X \sigma}^{\mathrm{LSDA}}=-3 / 2\left(\frac{3}{4 \pi}\right)^{1 / 3} \rho_{\sigma}^{4 / 3}$

and $f\left(w_{\sigma}\right)$ is the spin kinetic-energy-density enhancement factor

$f\left(w_{\sigma}\right)=\sum_{i=0}^{m} a_{i} w_{\sigma}^{i}$

where the variable $w_{\sigma}$ is a function of $t_{\sigma}$, and $t_{\sigma}$ is a function of the spin kinetic energy density $\tau_{\sigma}$ and spin density $\rho_{\sigma}$.

$w_{\sigma}=\left(t_{\sigma}-1\right) /\left(t_{\sigma}+1\right)$

$t_{\sigma}=\tau_{\sigma}^{\mathrm{LSDA}} / \tau_{\sigma}$ 
where

$\tau_{\sigma}^{\mathrm{LSDA}} \equiv \frac{3}{10}\left(6 \pi^{2}\right)^{2 / 3} \rho_{\sigma}^{5 / 3}$

The functional form of the exchange functional in M06$2 \mathrm{X}$ is the special case in which $h_{\mathrm{X}}\left(x_{\sigma}, z_{\sigma}\right)=0$; in this special case, the M06 functional form for exchange reduces to M05 functional form for exchange.

\subsection{Meta-GGA correlation functional}

The functional form of the M06 and M06-2X correlation functionals is the same as the functional form of the M06L or M06-HF functionals. This functional form is based on the M05 and VSXC correlation functionals. In the correlation functional, we treat the opposite-spin and parallel-spin correlation differently.

The opposite-spin M06 correlation energy is expressed as:

$E_{\mathrm{C}}^{\alpha \beta}=\int e_{\alpha \beta}^{\mathrm{UEG}}\left[g_{\alpha \beta}\left(x_{\alpha}, x_{\beta}\right)+h_{\alpha \beta}\left(x_{\alpha \beta}, z_{\alpha \beta}\right)\right] \mathrm{d} r$

where $g_{\alpha \beta}\left(x_{\alpha}, x_{\beta}\right)$ is defined as:

$g_{\alpha \beta}\left(x_{\alpha}, x_{\beta}\right)=\sum_{i=0}^{n} c_{\mathrm{C} \alpha \beta, i}\left(\frac{\gamma_{\mathrm{C} \alpha \beta}\left(x_{\alpha}^{2}+x_{\beta}^{2}\right)}{1+\gamma_{\mathrm{C} \alpha \beta}\left(x_{\alpha}^{2}+x_{\beta}^{2}\right)}\right)^{i}$

and $h_{\alpha \beta}\left(x_{\alpha \beta}, z_{\alpha \beta}\right)$ is defined in Eq. (5), with $x_{\alpha \beta}^{2} \equiv x_{\alpha}^{2}+x_{\beta}^{2}$ and $z_{\alpha \beta} \equiv z_{\alpha}+z_{\beta}$.

For parallel spins,

$E_{\mathrm{C}}^{\sigma \sigma}=\int e_{\sigma \sigma}^{\mathrm{UEG}}\left[g_{\sigma \sigma}\left(x_{\sigma}\right)+h_{\sigma \sigma}\left(x_{\sigma}, z_{\sigma}\right)\right] D_{\sigma} \mathrm{d} r$

where $g_{\sigma \sigma}\left(x_{\sigma}\right)$ is defined as:

$g_{\sigma \sigma}\left(x_{\sigma}\right)=\sum_{i=0}^{n} c_{\mathrm{C} \sigma \sigma, i}\left(\frac{\gamma_{\mathrm{C} \sigma \sigma} x_{\sigma}^{2}}{1+\gamma_{\mathrm{C} \sigma \sigma} x_{\sigma}^{2}}\right)^{i}$

and $h_{\sigma \sigma}\left(x_{\sigma}, z_{\sigma}\right)$ is defined in Eq. (5). $D_{\sigma}$ is the self-interaction correction factor

$D_{\sigma}=1-\frac{x_{\sigma}^{2}}{4\left(z_{\sigma}+C_{F}\right)}$

We note that $D_{\sigma}$ vanishes for any one-electron system [21] and that $e_{\alpha \beta}^{\mathrm{UEG}}$ and $e_{\sigma \sigma}^{\mathrm{UEG}}$ in Eqs. (12) and (14) are the UEG correlation energy density for the anti-parallel-spin and parallel spin cases [90]. The total M06 correlation energy of the new correlation functional is given by

$E_{\mathrm{C}}=E_{\mathrm{C}}^{\alpha \beta}+E_{\mathrm{C}}^{\alpha \alpha}+E_{\mathrm{C}}^{\beta \beta}$

The values of the two non-linear parameters in Eqs. (13) and (15) are taken from previous work $[12,14]$.

$\gamma_{\mathrm{C} \alpha \beta}=0.0031, \quad \gamma_{\mathrm{C} \sigma \sigma}=0.06$
The values of the three non-linear parameters $\alpha_{\mathrm{x}}, \alpha_{\mathrm{C} \alpha \beta}$, and $\alpha_{\mathrm{C} \sigma \sigma}$ in Eq. (5), as employed in Eqs. (6), (12), and (14), are taken from other previous work [21].

\subsection{Hybrid meta functional}

The hybrid exchange-correlation energy can be written as follows:

$E_{\mathrm{XC}}^{\mathrm{hyb}}=\frac{X}{100} E_{\mathrm{X}}^{\mathrm{HF}}+\left(1-\frac{X}{100}\right) E_{\mathrm{X}}^{\mathrm{DFT}}+E_{\mathrm{C}}^{\mathrm{DFT}}$

where $E_{\mathrm{X}}^{\mathrm{HF}}$ is the nonlocal Hartree-Fock (HF) exchange energy, $X$ is the percentage of Hartree-Fock exchange in the hybrid functional, $E_{\mathrm{X}}^{\mathrm{DFT}}$ is the local DFT exchange energy, and $E_{\mathrm{C}}^{\mathrm{DFT}}$ is the local DFT correlation energy.

We optimize $X$ along with the parameters in the new meta exchange and correlation functionals; the optimization procedure is given in the next section.

The M06 and M06-2X functionals may be classified as hybrid meta-generalized gradient-approximations (hybrid meta-GGAs). We will discuss such classifications further in Sect. 6.

\subsection{Optimization of the new hybrid meta-GGA}

All parameter optimizations were carried out in a selfconsistent fashion. The parameters $a_{i}$ in Eqs. (6) and (8), $c_{\mathrm{C} \alpha \beta, i}$ in Eq. (12) and (13), $c_{\mathrm{C} \sigma \sigma, i}$ in Eq. (14) and (15), $d_{i}$ in $h_{\mathrm{X}}\left(x_{\sigma}, z_{\sigma}\right)$ (Eqs. (5) and (6)), $d_{\mathrm{C} \alpha \beta, i}$ in $h_{\alpha \beta}\left(x_{\alpha \beta}, z_{\alpha \beta}\right)$ (Eqs. (5) and (12)) and $d_{\mathrm{C} \sigma \sigma, i}$ in $h_{\sigma \sigma}\left(x_{\sigma}, z_{\sigma}\right)$ (Eqs. (5) and (14)), along with the $X$ were determined by fitting to the data in the training set. To obtain the correct UEG limit, we enforce the following constraints:

$\left.a_{0}+d_{0}+X / 100\right)=1$
$c_{\mathrm{C} \alpha \beta, i}+d_{\mathrm{C} \alpha \beta, i}=1$
$c_{\mathrm{C} \sigma \sigma, i}+d_{\mathrm{C} \sigma \sigma, i}=1$

We optimized the parameters in M06 against accurate data to minimize (subject to two constraints specified below) a training function $F$ defined by

$$
\begin{aligned}
F= & \text { RMSEPB(MGAE109) + RMSE(IP13) } \\
& + \text { RMSE(EA13) + RMSE(PA8) + RMSE }(\text { DBH76) } \\
& +10 \times \text { RMSE(NCCE31) + RMSE }(\text { TMML30) } \\
& +\operatorname{RMSE}(\mathrm{ABDE} 4)+\mathrm{RMSE}(\mathrm{AE} 17) \\
& +\operatorname{RMSE}(\pi \mathrm{TC} 13)
\end{aligned}
$$

where RMSEPB is denotes root-mean-squared error (RMSE) per bond, RMSE denotes root mean square error, all databases except TMML30 are defined in Sect. 2 and Table 1, and TMML30 is the union of TMAE9 and MLBE21. 
Table 2 Optimized parameters in the M06 and M06-2X methods

\begin{tabular}{|c|c|c|c|c|c|c|}
\hline & $a_{i}$ & $c_{C \alpha \beta, i}$ & $c_{C \sigma \sigma, i}$ & $d_{i}$ & $d_{C \alpha \beta, i}$ & $d_{C \sigma \sigma, i}$ \\
\hline$i$ & \multicolumn{6}{|c|}{ M06 } \\
\hline 0 & 5.877943E-01 & $3.741539 \mathrm{E}+00$ & $5.094055 \mathrm{E}-01$ & $1.422057 \mathrm{E}-01$ & $-2.741539 \mathrm{E}+00$ & $4.905945 \mathrm{E}-01$ \\
\hline 1 & $-1.371776 \mathrm{E}-01$ & $2.187098 \mathrm{E}+02$ & $-1.491085 \mathrm{E}+00$ & 7.370319E-04 & $-6.720113 \mathrm{E}-01$ & $-1.437348 \mathrm{E}-01$ \\
\hline 2 & $2.682367 \mathrm{E}-01$ & $-4.531252 \mathrm{E}+02$ & $1.723922 \mathrm{E}+01$ & $-1.601373 \mathrm{E}-02$ & $-7.932688 \mathrm{E}-02$ & $2.357824 \mathrm{E}-01$ \\
\hline 3 & $-2.515898 \mathrm{E}+00$ & $2.936479 \mathrm{E}+02$ & $-3.859018 \mathrm{E}+01$ & & $1.918681 \mathrm{E}-03$ & $1.871015 \mathrm{E}-03$ \\
\hline 4 & $-2.978892 \mathrm{E}+00$ & $-6.287470 \mathrm{E}+01$ & $2.845044 \mathrm{E}+01$ & & $-2.032902 \mathrm{E}-03$ & $-3.788963 \mathrm{E}-03$ \\
\hline 5 & $8.710679 \mathrm{E}+00$ & & & & & \\
\hline 6 & $1.688195 \mathrm{E}+01$ & & & & & \\
\hline 7 & $-4.489724 \mathrm{E}+00$ & & & & & \\
\hline 8 & $-3.299983 \mathrm{E}+01$ & & & & & \\
\hline 9 & $-1.449050 \mathrm{E}+01$ & & & & & \\
\hline 10 & $2.043747 \mathrm{E}+01$ & & & & & \\
\hline 11 & $1.256504 \mathrm{E}+01$ & & & & & \\
\hline$X$ & \multicolumn{6}{|c|}{27} \\
\hline$i$ & \multicolumn{6}{|c|}{ M06-2X } \\
\hline 0 & $4.600000 \mathrm{E}-01$ & $8.833596 \mathrm{E}-01$ & $3.097855 \mathrm{E}-01$ & & $1.166404 \mathrm{E}-01$ & $6.902145 \mathrm{E}-01$ \\
\hline 1 & $-2.206052 \mathrm{E}-01$ & $3.357972 \mathrm{E}+01$ & $-5.528642 \mathrm{E}+00$ & & $-9.120847 \mathrm{E}-02$ & $9.847204 \mathrm{E}-02$ \\
\hline 2 & $-9.431788 \mathrm{E}-02$ & $-7.043548 \mathrm{E}+01$ & $1.347420 \mathrm{E}+01$ & & $-6.726189 \mathrm{E}-02$ & $2.214797 \mathrm{E}-01$ \\
\hline 3 & $2.164494 \mathrm{E}+00$ & 4.978271E+01 & $-3.213623 \mathrm{E}+01$ & & $6.720580 \mathrm{E}-05$ & $-1.968264 \mathrm{E}-03$ \\
\hline 4 & $-2.556466 \mathrm{E}+00$ & $-1.852891 \mathrm{E}+01$ & $2.846742 \mathrm{E}+01$ & & $8.448011 \mathrm{E}-04$ & $-6.775479 \mathrm{E}-03$ \\
\hline 5 & $-1.422133 \mathrm{E}+01$ & & & & & \\
\hline 6 & $1.555044 \mathrm{E}+01$ & & & & & \\
\hline 7 & $3.598078 \mathrm{E}+01$ & & & & & \\
\hline 8 & $-2.722754 \mathrm{E}+01$ & & & & & \\
\hline 9 & $-3.924093 \mathrm{E}+01$ & & & & & \\
\hline 10 & $1.522808 \mathrm{E}+01$ & & & & & \\
\hline 11 & $1.522227 \mathrm{E}+01$ & & & & & \\
\hline$X$ & & & & 54 & & \\
\hline
\end{tabular}

The optimization of the M06-2X functional proceeds in the same way except that we exclude TMML30 in Eq. (23). Since the training set for M06-2X is less diverse than the training set of M06, we eliminated the parameters $d_{0-5}$ in the M06-2X functional, so the UEG constraint for the M06$2 \mathrm{X}$ exchange part is reduced to

$a_{0}+(X / 100)=1$

We minimize the training function with respect to these parameters in a self-consistent way by solving the FockKohn-Sham equation using the basis sets and geometries described in Sect. 3.1 but subject to two constraints: $\left|c_{\mathrm{C} \alpha \beta, 0}\right|<5$ and $\left|c_{\mathrm{C} \sigma \sigma, 0}\right|<5$. Because of these constraints the training function is only approximately minimized, but the functional is more physical than for an unconstrained optimization. All optimized parameters for M06 and M06$2 \mathrm{X}$ are listed in Table 2.

\section{Acronyms}

The density functional literature has an abundance of acronyms. The reader is reminded that most of these are identified in Tables 1 and 3. Other acronyms are defined at first usage and summarized in the glossary in the appendix.

\section{Density functionals considered in this article}

In this article, we compare the results obtained by the new M06 and M06-2X functionals to those for 14 other functionals (BLYP [91,92], B3LYP [91-94], PBE [87], B98 [95], VSXC [21], PBEh [87,96], HFLYP [97], TPSSh [3], BMK [5], B97-3 [11], M05 [12] M05-2X [14], M06-L [16], and M06-HF [19]) and to results for HF theory. Table 3 lists all 16 density functionals considered in this work. In each case we specify the year it was first published, the functional 
Table 3 Tested density functionals

\begin{tabular}{|c|c|c|c|c|c|c|c|c|c|c|}
\hline \multirow[t]{2}{*}{ Method } & \multirow[t]{2}{*}{ Year } & \multirow[t]{2}{*}{$\operatorname{Ref}(s)$} & \multicolumn{4}{|l|}{ Exchange } & \multicolumn{4}{|c|}{ Correlation } \\
\hline & & & $\rho_{\sigma}, \nabla \rho_{\sigma}$ & $X$ & $\tau_{\sigma} ?$ & UEG? & $\rho_{\sigma}, \nabla \rho_{\sigma}$ & $\tau_{\sigma} ?$ & SCorF? & UEG? \\
\hline BLYP & 1988 & {$[91,92]$} & B88 & 0 & No & Yes & LYP & No & Yes & No \\
\hline B3LYP & 1994 & [91-94] & B88 & 20 & No & Yes & LYP & No & Yes & No \\
\hline PBE & 1996 & [87] & PBE & 0 & No & Yes & PBE & No & No & Yes \\
\hline B98 & 1998 & [95] & B98 & 21.98 & No & No & B98 & No & No & No \\
\hline $\mathrm{VSXC}^{\mathrm{a}}$ & 1998 & [21] & VSXC & 0 & Yes & No & VSXC & Yes & Yes & No \\
\hline $\mathrm{PBEh}^{\mathrm{b}}$ & 1999 & [96] & PBE & 25 & No & Yes & PBE & No & No & Yes \\
\hline HFLYP & 2002 & [97] & None & 100 & No & Yes & LYP & No & Yes & No \\
\hline TPSSh & 2003 & [3] & TPSS & 10 & Yes & Yes & TPSS & Yes & Yes & Yes \\
\hline BMK & 2004 & [5] & BMK & 42 & Yes & No & BMK & No & No & No \\
\hline B97-3 & 2005 & [11] & B97-3 & 26.93 & No & No & B97-3 & No & No & No \\
\hline M05 & 2005 & [12] & M05 & 28 & Yes & Yes & M05 & Yes & Yes & Yes \\
\hline M05-2X & 2005 & [14] & M05-2X & 56 & Yes & Yes & M05-2X & Yes & Yes & Yes \\
\hline M06-L & 2006 & [16] & M06-L & 0 & Yes & Yes & M06-L & Yes & Yes & Yes \\
\hline M06-HF & 2006 & [19] & M06-HF & 100 & Yes & Yes & M6-HF & Yes & Yes & Yes \\
\hline M06 & 2007 & Present work & M06 & 27 & Yes & Yes & M06 & Yes & Yes & Yes \\
\hline M06-2X & 2007 & Present work & M06-2X & 54 & Yes & Yes & M06-2X & Yes & Yes & Yes \\
\hline
\end{tabular}

a Also called VS98

b Also called PBE1PBE and PBE0

forms used for dependence on $\nabla \rho_{\sigma}$, whether or not the functional includes $\tau_{\sigma}$ in the exchange and correlation functional, and whether the correlation functional is self-correlationfree (SCorF). Table 3 also contains two columns (one for the exchange functional and one for the correlation functional) that describe whether or not the functional reduces to the correct uniform-electron-gas limit when $\nabla \rho_{\sigma} \rightarrow 0$ and $\tau_{\sigma} \rightarrow \tau_{\sigma}^{\mathrm{LSDA}}$. Readers can find the performance of many other hybrid functionals in our previous papers [6, $10,14,16]$ and those of others [5,7,98]. However, the present article focuses on a subset of popular, venerable, prototypical, and recent functionals. These functionals include high-performance representatives of each of four major classes of functionals: hybrid GGAs, hybrid meta-GGAs, local functionals, and functionals with full Hartree-Fock exchange. B3LYP, a hybrid GGA, is the most popular functional. B98, PBEh, and B97-3 are examples of the next generation of hybrid GGAs, with better average performance, and B98 is selected because it was judged by Curtiss et al. [99] to be the most accurate functional for the G3/05 test set of 454 energies. TPSSh and BMK represent two lines of development of hybrid meta GGAs, and M05 and M05$2 \mathrm{X}$ represent better performing hybrid meta GGAs; they are direct precursors of the M06 and M06-2X functionals that are the new functionals of the present article. As mentioned in Introduction, it is also sometimes desired or even required to use functionals with either no or full Hartree-Fock exchange. As examples of the former we consider BLYP, PBE, VSXC, and M06-L. As examples of the latter we consider HFLYP and M06-HF. Functionals with full Hartree-Fock exchange are well known to be problematic for transition metals, so HFLYP and M06-HF will not be applied to transition metals (nor will HF be so applied).

Various schemes are available for classifying density functionals, and it is useful to amplify on these schemes in more detail than was done in the previous paragraph. The first kind of scheme classifies them by their ingredients. The simplest such classification involves two classes: local functionals and nonlocal functionals. In Table 3, BLYP, PBE, VSXC, and M06-L are local $(X=0)$, and all others are nonlocal. At a finer level of distinction, one divides local functionals into local spin density approximations (LSDAs) that depend only on local spin density, generalized gradient approximations (GGAs) that also depend on the gradient of the local spin densities, and meta GGAs that also depend on local spin kinetic energy density. BLYP and PBE are GGAs, and VSXC and M06-L are meta GGAs. Nonlocal functionals are also called hybrid functionals to denote that, at least for currently available functionals, the nonlocality consists of adding the functional form of Hartree-Fock exchange. Adding Hartree-Fock exchange to GGAs or meta GGAs yields hybrid GGAs and hybrid meta GGAs, as classified in the previous paragraph. Our functional (M06-HF) with full Hartree-Fock exchange is a special case of a hybrid meta GGA. The ingredients of functionals may also be used to classify them in terms of Jacob's Ladder [100]; BLYP and PBE are on rung 2, VSXC 
and M06-L are on rung 3, and the other 12 functionals in Table 3 are on rung 4.

Finally, one may also classify functionals in terms of the strategy used in their design, as done by Scuseria and Staroverov [20]. They classified PBE, TPSS, and the exchange part of BLYP as functionals obtained by constraint satisfaction, the correlation part of BLYP and HFLYP as obtained by modeling the exchange-correlation hole, and B3LYP, PBEh, and TPSSh as functionals obtained by mixing exact and approximate exchange. Their scheme classifies B98, BMK, and B973 as empirical fits. They caution, however, that some functionals have elements from more than one class. As already mentioned in the introduction, the M05 and M05-2X functionals involve constraint satisfaction, empirical fitting, and mixing Hartree-Fock and approximate DFT exchange, M06$\mathrm{L}$ involves constraint satisfaction, modeling the exchangecorrelation hole, and empirical fitting, and M06-HF involves these components plus mixing Hartree-Fock and approximate exchange. The M06 and M06-2X functionals involve elements obtained by the same kinds of strategies as those in M06-HF.

\section{Results and discussion for energies}

The tables include both mean unsigned errors (MUEs), which are the averages of the absolute deviations of calculated values from database reference values, and mean signed errors (MSEs), which are used to detect systematic deviations. For atomization energies we use MUE per bond (MUEPB) and MSE per bond (MSEPB) because this allows $[4,49,101]$ one to make more meaningful comparisons between databases with different average sizes of molecules. To make the trends more clear, in every table that ends with a mean error column we will list the methods in increasing order of the values in the last column of a given table, which is the key overall error column for that table.

\subsection{Thermochemistry: AE, IP, EA, and PA results}

Table 4 summarizes the errors in atomization energies, ionization potentials, electron affinities, and proton affinities for all tested functionals. The table shows that the M06-2X, M06, M05-2X, and BMK functionals all perform 9-13\% better

Table 4 Mean errors (kcal/mol for ionization potentials (IP), electron affinities (EA), and proton affinities (PA) and kcal/mol per bond for atomization energies (AE))

\begin{tabular}{|c|c|c|c|c|c|c|c|c|c|}
\hline \multirow[t]{2}{*}{ Method } & \multicolumn{2}{|l|}{ AE109 } & \multicolumn{2}{|l|}{ IP13 } & \multicolumn{2}{|l|}{ EA13 } & \multicolumn{2}{|l|}{ PA8 } & \multirow{2}{*}{$\begin{array}{l}\text { SD143 } \\
\text { MUE }\end{array}$} \\
\hline & MSEPB & MUEPB & MSE & MUE & MSE & MUE & MSE & MUE & \\
\hline M06-2X & -0.18 & 0.40 & 1.06 & 2.54 & 1.30 & 2.07 & -0.19 & 1.75 & 0.82 \\
\hline M05-2X & -0.02 & 0.48 & 1.69 & 3.54 & 0.53 & 2.03 & -0.25 & 1.23 & 0.94 \\
\hline BMK & -0.04 & 0.47 & 2.74 & 4.21 & 0.28 & 1.56 & -0.49 & 1.07 & 0.94 \\
\hline M06 & 0.15 & 0.56 & -0.08 & 3.27 & 1.19 & 1.82 & 1.01 & 1.80 & 0.99 \\
\hline B98 & -0.50 & 0.64 & 1.99 & 3.21 & 0.30 & 1.84 & 1.44 & 1.44 & 1.03 \\
\hline M05 & -0.01 & 0.53 & -0.41 & 2.87 & 2.81 & 2.96 & 1.20 & 2.16 & 1.06 \\
\hline B97-3 & -0.37 & 0.59 & 1.56 & 3.51 & 0.82 & 2.07 & 2.46 & 2.46 & 1.10 \\
\hline VSXC & -0.18 & 0.57 & 2.31 & 3.29 & 0.22 & 2.80 & 1.83 & 1.98 & 1.10 \\
\hline M06-HF & -0.24 & 0.64 & 0.64 & 3.76 & 0.60 & 2.35 & 0.11 & 2.21 & 1.17 \\
\hline PBEh & 0.11 & 0.91 & 2.44 & 3.23 & 1.50 & 2.76 & 1.12 & 1.19 & 1.30 \\
\hline B3LYP & -0.69 & 0.91 & 3.58 & 4.72 & -1.51 & 2.29 & 0.18 & 1.02 & 1.39 \\
\hline M06-L & 0.05 & 0.85 & 0.76 & 3.09 & 2.96 & 3.84 & 2.01 & 2.06 & 1.39 \\
\hline TPSSh & -0.12 & 0.98 & 1.96 & 3.17 & 1.40 & 2.81 & 2.78 & 2.78 & 1.45 \\
\hline BLYP & -0.47 & 1.49 & -0.41 & 4.87 & -0.11 & 2.63 & -0.69 & 1.53 & 1.90 \\
\hline PBE & 2.80 & 3.03 & 2.11 & 3.58 & -1.20 & 2.22 & 0.04 & 1.35 & 2.91 \\
\hline HFLYP & -7.85 & 7.98 & 1.24 & 5.09 & 8.84 & 9.51 & 2.41 & 3.27 & 7.59 \\
\hline $\mathrm{HF}$ & -30.83 & 30.83 & -17.32 & 17.92 & 26.96 & 26.96 & 2.75 & 3.19 & 27.76 \\
\hline Average $(\mathrm{DFT})^{\mathrm{a}}$ & -0.47 & 1.32 & 1.45 & 3.62 & 1.24 & 2.85 & 0.93 & 1.83 & 1.69 \\
\hline Average $(\text { all })^{\mathrm{a}}$ & -2.26 & 3.05 & 0.34 & 4.46 & 2.76 & 4.27 & 1.04 & 1.91 & 3.23 \\
\hline
\end{tabular}

The MG3S basis set and QCISD/MG3 geometries are employed for the AE109, IP13, and EA13 databases; the 6-311+G(2df,2p) basis set and MP2(full)/6-31G(2df,p) geometries are employed for the PA8 database

MUEPB denotes mean unsigned error (MUE) per bond. MSE denotes mean signed error. The MUE for SD143 is defined as: MUE = $[$ MUEPB $\times 109$ $+\mathrm{MUE}(\mathrm{IP}) \times 13+\mathrm{MUE}(\mathrm{AE}) \times 13+\mathrm{MUE}(\mathrm{PA}) * 8] / 143$

"In all tables where the last two rows are averages, "Average(DFT)" is the average of that column for all density functionals in the table, and "Average(all)" is the average of that column over all entries in the table (DFT and HF) 
Table 5 Alkyl bond dissociation energies $\left(D_{\mathrm{e}}\right.$, $\mathrm{kcal} / \mathrm{mol}$ )

The B3LYP/6-31G(d) geometries are used in all calculations in this table, and the $6-311+\mathrm{G}(3 \mathrm{df}, 2 \mathrm{p})$ basis set is employed for all calculations involved in this table

\begin{tabular}{|c|c|c|c|c|c|c|}
\hline \multirow[t]{2}{*}{ Method } & \multicolumn{2}{|l|}{$\mathrm{R}-\mathrm{CH} 3$} & \multicolumn{2}{|c|}{$\mathrm{R}-\mathrm{OCH} 3$} & \multicolumn{2}{|c|}{ ABDE4 } \\
\hline & $\mathrm{R}=\mathrm{Me}$ & $\mathrm{R}=\mathrm{i}-\mathrm{Pr}$ & $\mathrm{R}=\mathrm{Me}$ & $\mathrm{R}=\mathrm{i}-\mathrm{Pr}$ & MSE & MUE \\
\hline Exp. & 97.39 & 95.00 & 89.79 & 91.51 & & \\
\hline M05-2X & 97.37 & 94.01 & 90.65 & 90.93 & -0.18 & 0.61 \\
\hline M06-2X & 97.58 & 94.05 & 91.49 & 91.64 & 0.27 & 0.74 \\
\hline BMK & 97.99 & 93.42 & 88.81 & 87.99 & -1.37 & 1.67 \\
\hline M06 & 96.83 & 91.58 & 89.50 & 88.16 & -1.90 & 1.90 \\
\hline PBE & 96.79 & 89.65 & 87.24 & 84.08 & -3.98 & 3.98 \\
\hline M06-HF & 97.32 & 98.02 & 96.88 & 99.57 & 4.52 & 4.56 \\
\hline B97-3 & 96.76 & 89.78 & 85.86 & 82.78 & -4.63 & 4.63 \\
\hline B98 & 95.73 & 89.10 & 86.06 & 83.31 & -4.87 & 4.87 \\
\hline PBEh & 95.23 & 89.29 & 85.63 & 83.59 & -4.98 & 4.98 \\
\hline M06-L & 96.32 & 88.96 & 84.49 & 81.75 & -5.54 & 5.54 \\
\hline M05 & 94.47 & 86.99 & 86.32 & 82.77 & -5.79 & 5.79 \\
\hline VSXC & 90.11 & 87.22 & 81.16 & 83.72 & -7.87 & 7.87 \\
\hline B3LYP & 91.58 & 85.01 & 82.58 & 80.06 & -8.62 & 8.62 \\
\hline TPSSh & 90.47 & 84.12 & 82.08 & 79.62 & -9.35 & 9.35 \\
\hline BLYP & 90.31 & 82.64 & 81.09 & 77.50 & -10.53 & 10.53 \\
\hline HFLYP & 89.39 & 86.17 & 76.49 & 77.36 & -11.07 & 11.07 \\
\hline $\mathrm{HF}$ & 65.57 & 62.19 & 52.39 & 52.86 & -35.17 & 35.17 \\
\hline \multicolumn{3}{|c|}{ Average (DFT) } & & & -4.74 & 5.42 \\
\hline \multicolumn{3}{|c|}{ Average (all) } & & & -6.53 & 7.17 \\
\hline
\end{tabular}

than B98 for this standard thermochemical data, which is similar to the kind of data most often used to test electronic methods like DFT. An important feature of our work though is to test the density functionals more broadly, as we do in the rest of this article.

\subsection{Trends in alkyl bond dissociation energies}

Predicting the dependence of alkyl bond dissociation energies on the size of the alkyl groups has proved to be difficult for many density functionals [60]. Table 5 summarizes the results for the trends in $\mathrm{R}-\mathrm{X}$ BDEs $(\mathrm{R}=$ methyl and isopropyl; $\mathrm{X}=\mathrm{CH}_{3}$ and $\mathrm{OCH}_{3}$ ). This table shows that M05-2X and M06-2X have excellent performance, and BMK and M06 also do much better than all other functionals tested.

\subsection{Tests for $\pi$ systems}

The $\pi$ TC13 database $[16,40]$ consists of the $\pi$ IE3/06 database of three isomeric energy differences between allene and propyne as well as higher homologs (which correspond to cumulenes and poly-ynes) [40,102], the PA-CP5/06 database of the proton affinities of five conjugated polyenes, and the PA-SB5/06 database of the proton affinities of the five conjugated Schiff bases. The cumulene $\leftrightarrow$ poly-yne isomerizations are another notoriously difficult problem of DFT [40,102].
Table 6 shows that M06-HF, M05, M06-2X, and M06 all do reasonably well for this problem. Proton affinities of conjugated $\pi$ systems are an interesting test of DFT because many density functionals greatly overestimate the polarizabilities and hyperpolarizabilities of conjugated $\pi$ systems $[103,104]$. Table 6 shows that M06-2X performs strikingly well for proton affinities of conjugated polyenes. The second and third best methods for this difficult problem are M06-HF and M05-2X, respectively.

\subsection{Tests for hydrocarbons}

The HC7 database consists of seven difficult cases involving medium-range correlation energies in hydrocarbons; HC7 is the combination of the previous HC5 database [35] with two isodesmic reactions (involving adamantane and bicycle [2.2.2] octane) that were singled out as difficult cases by Grimme [17]. The first two data in HC7 are isomerization energies of $(\mathbf{C H})_{12}$ isomer $\mathbf{1}, \mathbf{2 2}$, and $\mathbf{3 1}[35,105]$ and shown in Fig. 1. The third datum is energy of reaction of the following octane isomerization [106]:

$\left(\mathrm{CH}_{3}\right)_{3} \mathrm{CC}\left(\mathrm{CH}_{3}\right)_{3} \rightarrow n-\mathrm{C}_{8} \mathrm{H}_{18}$

The fourth To seventh data are energies of reaction for the following reactions [19]: 
Table 6 Results for $\pi$ systems

\begin{tabular}{|c|c|c|c|c|c|c|c|}
\hline \multirow[t]{2}{*}{ Method } & \multicolumn{2}{|l|}{$\pi \mathrm{IE} 3$} & \multicolumn{2}{|l|}{ PA-P5 } & \multicolumn{2}{|c|}{ PA-SB5 } & \multirow{2}{*}{$\begin{array}{l}\pi \mathrm{TC} 13 \\
\text { BMUE }^{\mathrm{a}}\end{array}$} \\
\hline & MSE & MUE & MSE & MUE & MSE & MUE & \\
\hline M06-2X & 1.6 & 1.6 & 0.4 & 0.7 & 1.7 & 2.0 & 1.4 \\
\hline M06-HF & 1.1 & 1.1 & -3.9 & 3.9 & 0.8 & 0.8 & 1.9 \\
\hline M05-2X & 3.0 & 3.0 & 2.1 & 2.1 & 3.9 & 3.9 & 3.0 \\
\hline M06 & 2.0 & 2.0 & 5.7 & 5.7 & 4.2 & 4.4 & 4.0 \\
\hline BMK & 3.9 & 3.9 & 4.3 & 4.3 & 5.1 & 5.1 & 4.4 \\
\hline M05 & 1.8 & 1.8 & 7.9 & 7.9 & 5.5 & 5.5 & 5.1 \\
\hline PBE & 8.8 & 8.8 & 4.2 & 4.2 & 4.5 & 4.8 & 5.9 \\
\hline PBEh & 5.7 & 5.7 & 5.7 & 5.7 & 6.5 & 6.5 & 6.0 \\
\hline B3LYP & 6.2 & 6.2 & 5.8 & 5.8 & 5.9 & 5.9 & 6.0 \\
\hline BLYP & 8.7 & 8.7 & 4.9 & 5.5 & 4.3 & 4.8 & 6.3 \\
\hline M06-L & 5.4 & 5.4 & 7.8 & 7.8 & 6.1 & 6.1 & 6.4 \\
\hline B98 & 6.3 & 6.3 & 7.3 & 7.3 & 7.3 & 7.3 & 6.9 \\
\hline B97-3 & 5.4 & 5.4 & 7.7 & 7.7 & 8.0 & 8.0 & 7.0 \\
\hline TPSSh & 7.2 & 7.2 & 8.6 & 8.6 & 7.8 & 7.8 & 7.9 \\
\hline VSXC & 8.4 & 8.4 & 8.3 & 8.3 & 8.1 & 8.1 & 8.3 \\
\hline HFLYP & -1.8 & 2.5 & 11.4 & 11.4 & 12.0 & 12.0 & 8.6 \\
\hline $\mathrm{HF}$ & -2.2 & 2.7 & 12.7 & 12.7 & 10.9 & 10.9 & 8.8 \\
\hline Average (DFT) & 4.6 & 4.9 & 5.5 & 6.0 & 5.7 & 5.8 & 5.6 \\
\hline Average (all) & 4.2 & 4.7 & 5.9 & 6.4 & 6.0 & 6.1 & 5.8 \\
\hline
\end{tabular}

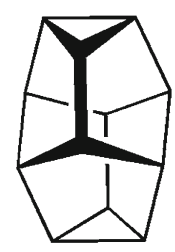

1
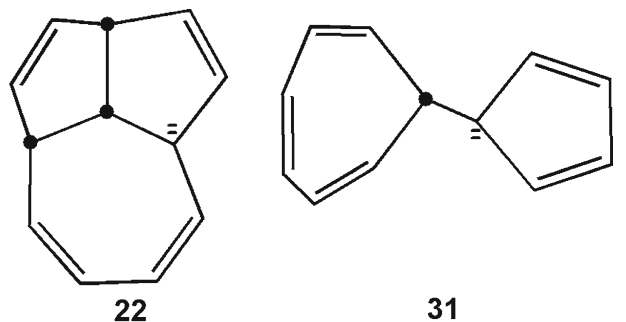

31
Fig. 1 Structures of $(\mathrm{CH})_{12}$ isomers 1, 22, and $\mathbf{3 1}$ in Ref. [105]

$$
\begin{aligned}
& n-\mathrm{C}_{6} \mathrm{H}_{14}+4 \mathrm{CH}_{4} \rightarrow 5 \mathrm{C}_{2} \mathrm{H}_{6} \\
& n-\mathrm{C}_{8} \mathrm{H}_{18}+6 \mathrm{CH}_{4} \rightarrow 7 \mathrm{C}_{2} \mathrm{H}_{6} \\
& \text { adamantane } \rightarrow 3 \mathrm{C}_{2} \mathrm{H}_{4}+2 \mathrm{C}_{2} \mathrm{H}_{2} \\
& \text { bicyclo[2.2.2] octane } \rightarrow 3 \mathrm{C}_{2} \mathrm{H}_{4}+\mathrm{C}_{2} \mathrm{H}_{2}
\end{aligned}
$$

Table 7 shows that the performance of the most popular functional, B3LYP, is worse than the performance of $\mathrm{HF}$ theory for this database. Encouragingly, the M06-HF, M052X, M06-2X, and M06 functionals all perform well for this difficult database. Even M06-L is better than most pervious functionals.

\subsection{Tests for difficult cases}

Table 8 summarizes the results for ten difficult cases (the DC10 database). The first datum is the binding energy of a
Lewis acid-base complex $\left(\mathrm{HCN} \cdots \mathrm{BF}_{3}\right)$, which has been shown to be a difficult case for DFT by Phillips and Cramer [107]. The second datum is the atomization energy of $\mathrm{O}_{3}$, a notorious [108-110] main-group multireference system for which the best estimate for the atomization energy is taken from Feller and Peterson [111]. The third datum is the energy of reaction for $\mathrm{C}_{6} \mathrm{Cl}_{6}+6 \mathrm{HCl} \rightarrow 6 \mathrm{Cl}_{2}+\mathrm{C}_{6} \mathrm{H}_{6}$; Grimme [17] showed that it is a difficult case for DFT. The fourth to sixth data are the atomization energies of non-hydrogen-containing hypervalent compounds involving second row elements, in particular, $\mathrm{P}_{4}, \mathrm{SF}_{6}$, and $\mathrm{PF}_{5}$; these compounds are difficult cases for DFT and for WFT-based G3-type methods [99, 112]. The seventh datum is the energy of reaction for $\mathrm{P}_{4} \mathrm{O}_{10} \rightarrow \mathrm{P}_{4}+5 \mathrm{O}_{2}$; Grimme [17] showed that it is also a difficult case for DFT. The last three data are the atomization energies of $\mathrm{C}_{6} \mathrm{~F}_{6}, \mathrm{Si}\left(\mathrm{OCH}_{3}\right)_{4}$, and urotopin $\left(\mathrm{C}_{6} \mathrm{H}_{12} \mathrm{~N}_{4}\right)$; the atomization energy for these big molecules are also challenging cases for DFT, as shown by Curtiss et al. [99,112] and by Grimme [113]. The best estimates of the last eight data are obtained using the standard enthalpies of formation from Cioslowski et al. [114] and thermal corrections and zeropoint vibrational energies (ZPVE) calculated at the MP2/6$31+\mathrm{G}(\mathrm{d}, \mathrm{p})$ level of theory, with a scaling factor [49] of 0.97 for the MP2/6-31+G(d,p) ZPVE. Note that the experimental data quoted by Grimme [17] for $\mathrm{P}_{4} \mathrm{O}_{10}$ and adamantane appear to be incorrect.

As shown in Table 8, the most popular density functional, B3LYP, gives an MUE of $20.7 \mathrm{kcal} / \mathrm{mol}$ for these ten difficult 
Table 7 Results for the HC7 database

\begin{tabular}{|c|c|c|c|c|c|c|c|c|c|}
\hline \multirow[t]{2}{*}{ Method } & \multirow[t]{2}{*}{ E22-E1 } & \multirow[t]{2}{*}{ E31-E1 } & \multirow[t]{2}{*}{ Octane isomerization } & \multirow[t]{2}{*}{$\Delta E($ rxn a $)$} & \multirow[t]{2}{*}{$\Delta E(\mathrm{rxn} b)$} & \multirow[t]{2}{*}{$\Delta E(\operatorname{rxn} \mathrm{c})$} & \multirow[t]{2}{*}{$\Delta E($ rxn d $)$} & \multicolumn{2}{|l|}{$\mathrm{HC} 7$} \\
\hline & & & & & & & & MSE & MUE \\
\hline Best estimate & 14.34 & 25.02 & 1.90 & 16.33 & 24.84 & 127.22 & 193.99 & & \\
\hline M06-2X & 16.31 & 23.63 & 2.12 & 14.65 & 22.08 & 129.41 & 199.27 & 0.55 & 2.21 \\
\hline M06-HF & 14.21 & 23.87 & 3.64 & 15.35 & 23.02 & 130.76 & 201.98 & 1.31 & 2.48 \\
\hline M06 & 19.30 & 26.17 & 3.03 & 14.51 & 21.87 & 130.05 & 199.02 & 1.47 & 2.84 \\
\hline M06-L & 16.29 & 19.87 & 1.24 & 12.82 & 19.34 & 123.95 & 191.43 & -2.67 & 3.23 \\
\hline M05-2X & 14.94 & 22.89 & 2.04 & 14.74 & 22.23 & 133.63 & 206.45 & 1.90 & 3.71 \\
\hline PBE & 13.81 & 18.45 & -5.17 & 12.36 & 18.64 & 124.90 & 193.65 & -3.86 & 3.86 \\
\hline BMK & 21.47 & 31.04 & -2.07 & 12.70 & 19.28 & 133.25 & 204.83 & 2.41 & 6.17 \\
\hline TPSSh & 15.53 & 20.27 & -5.93 & 10.87 & 16.43 & 117.60 & 183.72 & -6.45 & 6.79 \\
\hline B97-3 & 12.38 & 18.26 & -7.95 & 11.02 & 16.62 & 117.58 & 183.54 & -7.46 & 7.46 \\
\hline M05 & 30.23 & 37.73 & -7.10 & 12.06 & 18.17 & 124.94 & 191.50 & 0.55 & 7.62 \\
\hline B98 & 6.56 & 11.82 & -6.50 & 11.49 & 17.37 & 118.94 & 185.40 & -8.37 & 8.37 \\
\hline PBEh & 23.49 & 32.36 & -4.56 & 12.37 & 18.67 & 139.73 & 214.70 & 4.73 & 9.47 \\
\hline VSXC & 3.62 & 1.95 & 32.15 & 20.13 & 30.37 & 113.33 & 181.27 & -2.97 & 14.28 \\
\hline $\mathrm{HF}$ & 2.52 & 11.90 & -10.75 & 10.09 & 15.27 & 100.92 & 161.41 & -16.04 & 16.04 \\
\hline HFLYP & 24.38 & 40.70 & -3.34 & 12.71 & 19.19 & 156.59 & 239.91 & 12.35 & 16.50 \\
\hline B3LYP & -1.09 & 1.25 & -7.97 & 11.16 & 16.85 & 103.02 & 163.40 & -16.72 & 16.72 \\
\hline BLYP & -11.50 & -13.34 & -9.58 & 10.64 & 16.06 & 83.93 & 136.38 & -27.29 & 27.29 \\
\hline Average (DFT) & & & & & & & & -3.16 & 8.69 \\
\hline Average (all) & & & & & & & & -3.92 & 9.12 \\
\hline
\end{tabular}

The MG3S basis set and MP2/6-311+G(d,p) geometries are employed for all calculations

Reactions (a), (b), (c), and (d) are defined in Sect. 7.4

cases. The best performing functional in Table 8 is BMK, followed by M06-2X and M05-2X.

\subsection{Thermochemical kinetics}

Table 9 gives the mean errors for the barrier height databases. We also tabulated a balanced MUE (BMUE) that is defined as 1/4 times the MUE for heavy-atom transfer barrier heights plus 1/4 times the MUE for $\mathrm{S}_{\mathrm{N}} 2$ barrier heights plus $1 / 4$ times the MUE for unimolecular and association barrier heights plus 1/4 times the MUE for hydrogen transfer barrier heights.

Table 9 shows that the BMK, M06-2X, and M05-2X functionals give the best results for heavy-atom-transfer barrier height calculations. M05, B97-3, and BMK have the best performance for nucleophilic substitution barrier height calculations. M06-2X, B97-3, and M06-HF give the best performance for unimolecular and association barrier height calculations. The M06-2X, BMK, and M05-2X functionals give the best performance for hydrogen-transfer barrier height calculations, and they also give the lowest values of BMUE, which means they give the best overall performance for barrier height calculations.
Another quantity, average MUE or AMUE, is defined as:

$\operatorname{AMUE}=[\operatorname{MUE}(\Delta \mathrm{E}, 38)+\operatorname{MMUE}(\mathrm{DBH} 76)] / 2$

where $\operatorname{MUE}(\Delta \mathrm{E}, 38)$ is the mean unsigned error in the energy of reactions for the 38 reactions in the DBH76 database. If one prefers to use AMUE as a criterion to justify the performance of a DFT method for thermochemical kinetics, the M06 functional gives better performance than M05 because M06 has much better performance for energies of reaction than M05. With this one exception, the 14 highest ranking functionals in Table 9 for AMUE are in the same order as the 14 highest ranking for BMUE.

\subsection{Noncovalent interactions}

The mean errors for noncovalent interactions are listed in Tables 10 and 11. In Table 10, we use "no-cp" to denote calculations without the counterpoise correction for the BSSE, and we use "cp" to denote calculations that do include the counterpoise correction for the BSSE. In Tables 10 and 11, we also defined a mean MUE:

$\operatorname{MMUE}=[\operatorname{MUE}($ no-cp $)+\operatorname{MUE}(\mathrm{cp})] / 2$ 


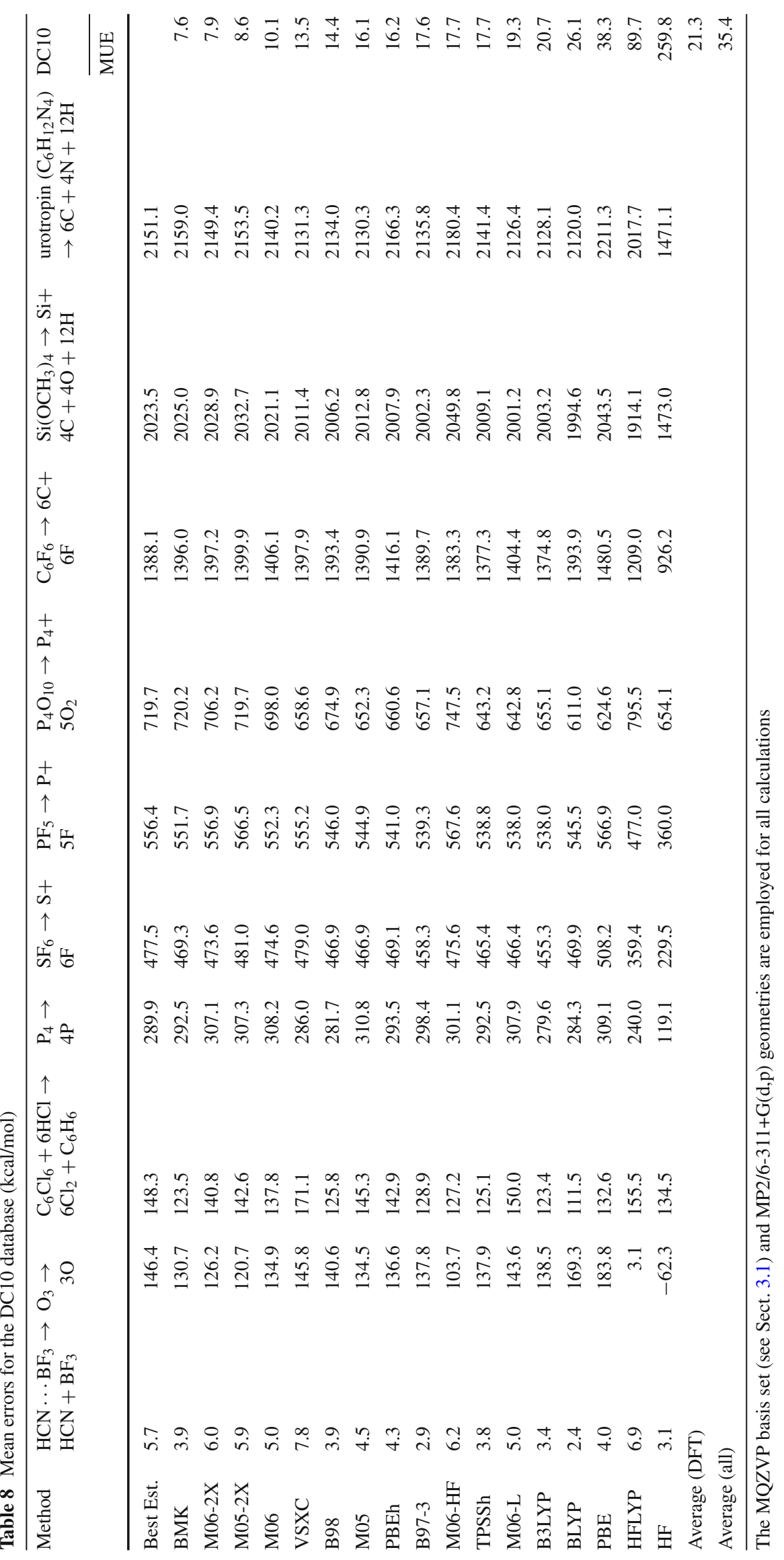


As in our previous work $[10,14,37]$ we use MMUE to judge the performance of density functionals for noncovalent interactions, but our conclusions would not be very different if we used either no-cp results or $\mathrm{cp}$ results.

Charge transfer complexes have long been recognized as a difficulty for density functionals [115,116]; Table 10 shows that M06-2X, M05-2X, M06-HF, and M05 give the best performance. For the dipole interactions, M05, HFLYP, and M05-2X are the best performers.

Weak interactions and $\pi-\pi$ stacking interactions play a dominant role in stabilizing various biopolymers, for example, the double helix structure of DNA [117,118], and such interactions are also important for protein folding [119] and supramolecular design $[120,121]$. Table 10 shows the best functionals for weak interactions are M05-2X, M05, and HFLYP. However, M06-2X, M06-HF, and M06 give the best performance for $\pi-\pi$ stacking interactions, which until recently were considered $[122,123]$ to be a major failing of DFT.

The overall performance for noncovalent interactions can be judged by the balanced MMUE for NC31, which is defined as:

$$
\begin{aligned}
\text { BMMUE }= & {[\operatorname{MMUE}(\mathrm{HB})+\operatorname{MMUE}(\mathrm{CT})+\operatorname{MMUE}(\mathrm{DI})} \\
& +\operatorname{MMUE}(\mathrm{WI})+\operatorname{MMUE}(\mathrm{PPS})] / 5
\end{aligned}
$$

If we use BMMUE as a criterion to evaluate the overall performance of DFT methods for noncovalent interactions, we can see from Table 10 that M06-2X, M05-2X, M06, and M05 are the best functionals in the present study. They are also best for hydrogen bonding. The M05 family of M05 and M05-2X have BMMUEs of 0.52 and $0.33 \mathrm{kcal} / \mathrm{mol}$, respectively, while the family of four M06-type functionals have BMMUEs in the range of $0.27-0.55 \mathrm{kcal} / \mathrm{mol}$. The best previous hybrid functionals in Table 10 are PBEh and B98 with $0.74-0.78 \mathrm{kcal} / \mathrm{mol}$, and the local PBE functional has a BMMUE of $1.14 \mathrm{kcal} / \mathrm{mol}$.

Table 11 presents results for the S22 database and its three components. S22 is a large, diverse, noncovalent database that is not in the training set of the M06 and M06-2X functionals (nor is it in the training set for M05, M05-2X, M06-L, or M06-HF). The JHB7 component of the S22 database contains hydrogen bonded complexes. Jurecka et al. use the language of "predominant dispersion stabilization" for the complexes in JDL8, but the word "dispersion" seems to be interpreted differently by different workers with some researchers restricting it to long-range forces only. At the equilibrium geometry of complexes, the repulsive force is equal and opposite to the attractive force, so one is not in the long-range regime; thus we prefer to say "dispersion-like" or "medium-range" correlation energy. The complexes in JM7 are bound by a mixture of electrostatic and dispersion-like forces. It is encouraging that Table 11 shows that M06-2X,
M05-2X, and M06 perform best for the S22 database of biologically important interactions. In fact the Minnesota functionals as a group are best for both the NC31 database and the S22 database.

\subsection{Thermochemistry, kinetics, and noncovalent} interactions

We can use the results in Sects. 7.1-7.7 to assess the performance of the functionals over broad amounts of data. For example, the average of the results for database in categories IA and IB (see Table 1) give a balanced assessment for thermochemistry (TC) and thermochemical kinetics (TK):

$$
\begin{aligned}
\operatorname{MUE}(\mathrm{TC} 177)= & {[143 \mathrm{MUE}(\mathrm{SD} 143)+4 \operatorname{MUE}(\mathrm{ABDE} 4)} \\
& +13 \operatorname{BMUE}(\pi \mathrm{TC} 13)+7 \operatorname{MUE}(\mathrm{HC} 7) \\
& +10 \mathrm{MUE}(\mathrm{DC} 10)] / 177 \\
\operatorname{BMUE}(\mathrm{TK} 253)= & {[\operatorname{MUE}(\mathrm{TC} 177)+\mathrm{BMUE}(\mathrm{DBH} 76)] / 2 }
\end{aligned}
$$

Similarly we can assess the functionals even more broadly with the balanced MUE for thermochemistry, kinetics, and noncovalent interactions:

$$
\begin{aligned}
\text { BMUE }(\text { NCIE } 53)= & {[\text { BMMUE }(\text { NCCE31 })} \\
& + \text { BMMUE }(\text { S22 })] / 2 \\
\operatorname{BMUE}(\text { TKNC306 })= & {[\text { MUE }(\text { TC } 177)+\text { BMUE }(\text { DBH } 76)} \\
& + \text { BMUE }(\text { NCIE53) }] / 3
\end{aligned}
$$

Table 12 shows that the most accurate method for thermochemistry and kinetics, as judged by the TK253 database, is M06-2X, followed by M05-2X and BMK. When noncovalent interactions are also considered, the best methods, as judged by the thermochemistry, kinetics, and noncovalent interaction database TKNC306, are M06-2X, M05-2X, M06, BMK, M06-HF, and M05, in that order. The success of M06HF is very noteworthy because for a long time it was widely believed that one could not obtain high accuracy with full Hartree-Fock exchange.

\subsection{Spectroscopy}

Tables 13-17 show the results of time-dependent DFT (TDDFT) for spectroscopy. We judge the performance for spectroscopy primarily in terms of the mean unsigned errors (MUEs) for noncharge-transfer (non-CT) and charge transfer (CT) excitations in a test set. The non-CT transitions are denoted VR for valence and Rydberg; the MUE for this class of electronic excitations is defined as

$$
\begin{aligned}
\operatorname{MUE}(\operatorname{VRES} 41)= & {[21 \mathrm{MUE}(\operatorname{VES} 21)} \\
& +20 \mathrm{MUE}(\operatorname{RES} 20)] / 41
\end{aligned}
$$


Table 9 Mean errors for thermochemical kinetics

\begin{tabular}{|c|c|c|c|c|c|c|c|c|c|c|}
\hline \multirow[t]{2}{*}{ Methods } & \multicolumn{2}{|c|}{ НАТВН12 } & \multicolumn{2}{|c|}{ NSBH16 } & \multicolumn{2}{|c|}{ UABH10 } & \multicolumn{2}{|c|}{ Hydrogen Transfer (38) } & \multirow[t]{2}{*}{ AMUE } & \multirow{2}{*}{$\begin{array}{l}\text { DBH76 } \\
\text { BMUE }\end{array}$} \\
\hline & MSE & MUE & MSE & MUE & MSE & MUE & MSE & MUE & & \\
\hline M06-2X & -0.81 & 1.61 & 0.77 & 1.22 & 0.32 & 0.92 & -0.51 & 1.13 & 1.06 & 1.22 \\
\hline BMK & -1.21 & 1.49 & 0.75 & 0.91 & 0.80 & 1.58 & -0.82 & 1.32 & 1.29 & 1.32 \\
\hline M05-2X & 1.15 & 2.00 & -0.79 & 1.48 & 0.91 & 1.77 & -0.39 & 1.34 & 1.39 & 1.65 \\
\hline B97-3 & -2.41 & 2.41 & -0.24 & 0.80 & 0.57 & 1.42 & -2.11 & 2.27 & 1.48 & 1.72 \\
\hline M05 & -2.84 & 3.79 & 0.00 & 0.80 & 0.69 & 2.24 & -1.20 & 1.93 & 2.06 & 2.19 \\
\hline M06 & -3.33 & 3.38 & -1.53 & 1.78 & 0.04 & 1.69 & -1.94 & 2.00 & 1.88 & 2.21 \\
\hline M06-HF & 1.79 & 4.39 & -0.71 & 1.61 & 0.54 & 1.45 & 1.14 & 2.06 & 2.22 & 2.38 \\
\hline B98 & -5.18 & 5.18 & -2.96 & 2.96 & -0.31 & 1.97 & -4.16 & 4.16 & 2.41 & 3.57 \\
\hline PBEh & -6.62 & 6.62 & -1.87 & 2.05 & -0.58 & 2.16 & -4.22 & 4.22 & 2.75 & 3.76 \\
\hline M06-L & -5.58 & 5.93 & -3.58 & 3.58 & 0.04 & 1.86 & -4.14 & 4.16 & 3.02 & 3.88 \\
\hline B3LYP & -8.49 & 8.49 & -3.25 & 3.25 & -1.42 & 2.02 & -4.13 & 4.23 & 3.08 & 4.50 \\
\hline VSXC & -7.44 & 7.44 & -5.30 & 5.30 & -0.91 & 2.40 & -4.86 & 4.87 & 3.45 & 5.00 \\
\hline TPSSh & -11.51 & 11.51 & -5.78 & 5.78 & -2.94 & 3.23 & -5.97 & 5.97 & 4.57 & 6.62 \\
\hline HFLYP & 9.67 & 11.96 & 5.26 & 5.33 & 3.13 & 3.54 & 6.42 & 7.22 & 4.77 & 7.01 \\
\hline $\mathrm{HF}$ & 14.86 & 16.87 & 6.67 & 6.67 & 2.70 & 3.82 & 1.83 & 6.28 & 7.19 & 8.41 \\
\hline BLYP & -14.66 & 14.66 & -8.40 & 8.40 & -3.38 & 3.51 & -7.52 & 7.52 & 5.67 & 8.52 \\
\hline PBE & -14.93 & 14.93 & -6.97 & 6.97 & -2.94 & 3.35 & -9.32 & 9.32 & 5.65 & 8.64 \\
\hline Average (DFT) & -4.52 & 6.61 & -2.16 & 3.26 & -0.34 & 2.19 & -2.73 & 3.98 & 2.92 & 4.01 \\
\hline Average (all) & -3.38 & 7.22 & -1.64 & 3.46 & -0.16 & 2.29 & -2.46 & 4.12 & 3.17 & 4.27 \\
\hline
\end{tabular}

The QCISD/MG3 geometries and MG3S basis set are used for calculations in this table

AMUE is defined in as: $\mathrm{AMUE}=[\mathrm{MUE}(\triangle \mathrm{E}, 38)+\mathrm{MMUE}] / 2$, where $\mathrm{MUE}(\Delta \mathrm{E}, 38)$ is the mean unsigned error for the energy of reactions for the 38 reactions involved in this table. AMUE is one measure of the quality of a method for kinetics

BMUE denotes balanced mean unsigned error ( $\mathrm{kcal} / \mathrm{mol}$ ). BMUE for DBH76 is calculated by averaging the numbers in columns 3, 5, 7, and 9; this weighs each of the four component databases equally, so that their contributions are balanced even though they have different numbers of data

where MUE(VES21) is the mean unsigned error for the excitation energies of the 21 valence transitions of $\mathrm{N}_{2}, \mathrm{CO}$, formaldehyde, and tetracene in Tables 13-16, and MUE(RES20) is the mean unsigned error for the excitation energies of the twenty Rydberg transitions of $\mathrm{N}_{2}, \mathrm{CO}$, and formaldehyde in Tables 13-15.

The MUE for charge transfer excitations is

$$
\begin{aligned}
& \operatorname{MUE}(\mathrm{CTES} 3)=[\text { error in CT transition of tetracene } \mid \\
& + \text { error in } \mathrm{NH}_{3} \cdots \mathrm{F}_{2} \text { at } 6 \AA \text { | } \\
& + \text { |error in } \mathrm{C}_{2} \mathrm{H}_{4} \cdots \mathrm{C}_{2} \mathrm{~F}_{4} \text { at } 8 \AA \text { |] } / 3
\end{aligned}
$$

The distances of the two CT pairs of Eq. (34) are defined in Fig. 2, which also shows the orientation of the subunits. The test data for the charge transfer transitions are less reliable than the other data used for testing in the present paper. For example, an alternative treatment of the experimental data [124] leads to a gas-phase CT excitation energy of $2.74 \mathrm{eV}$, and the other two best estimates should also be used with caution, but the uncertainty are not large enough to change our conclusions.

The results for all the transitions are in Tables 13-16, along with best estimates $[19,125-130]$ to which we compare. The

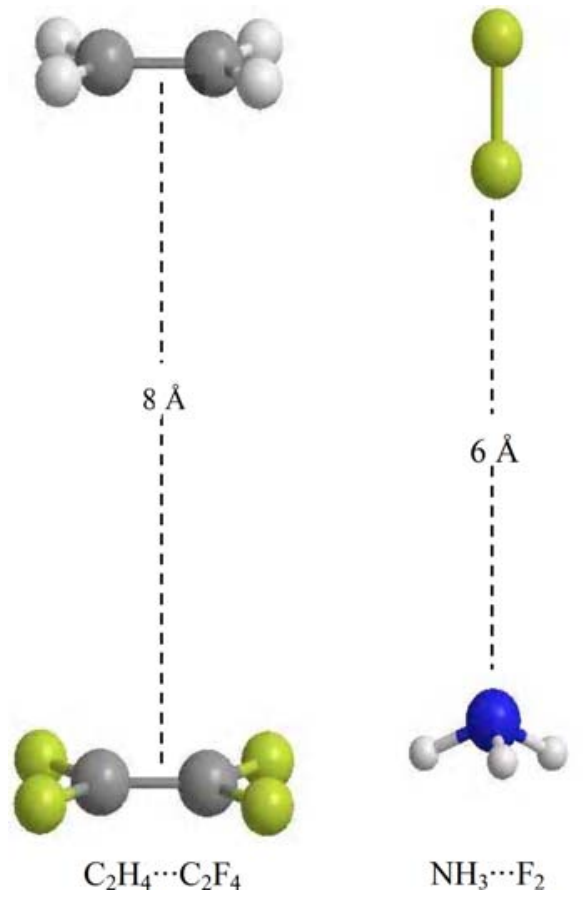

Fig. 2 Structures of $\mathrm{C}_{2} \mathrm{H}_{4} \cdots \mathrm{C}_{2} \mathrm{~F}_{4}$ and $\mathrm{NH}_{3} \cdots \mathrm{F}_{2}$ complexes 
Table 10 Mean errors for noncovalent databases $(\mathrm{kcal} / \mathrm{mol})$

\begin{tabular}{|c|c|c|c|c|c|c|c|c|c|c|c|c|c|c|c|c|}
\hline \multirow[t]{3}{*}{ Method } & \multicolumn{3}{|c|}{ HB6/04 } & \multicolumn{3}{|c|}{ CT7/04 } & \multicolumn{3}{|c|}{ DI6/04 } & \multicolumn{3}{|c|}{ WI7/05 } & \multicolumn{3}{|c|}{ PPS5/05 } & \multirow{3}{*}{$\frac{\text { NCCE31 }}{\text { BMMUE }}$} \\
\hline & \multicolumn{2}{|l|}{ MUE } & \multirow[t]{2}{*}{ MMUE } & \multicolumn{2}{|l|}{ MUE } & \multirow[t]{2}{*}{ MMUE } & \multicolumn{2}{|l|}{ MUE } & \multirow[t]{2}{*}{ MMUE } & \multicolumn{2}{|l|}{ MUE } & \multirow[t]{2}{*}{ MMUE } & \multicolumn{2}{|l|}{ MUE } & \multirow[t]{2}{*}{ MMUE } & \\
\hline & no-cp & $\mathrm{cp}$ & & no-cp & $\mathrm{cp}$ & & no-cp & $\mathrm{cp}$ & & no-cp & $\mathrm{cp}$ & & no-cp & $\mathrm{cp}$ & & \\
\hline M06-2X & 0.45 & 0.25 & 0.35 & 0.36 & 0.27 & 0.32 & 0.25 & 0.31 & 0.28 & 0.17 & 0.09 & 0.13 & 0.21 & 0.39 & 0.30 & 0.27 \\
\hline M05-2X & 0.40 & 0.20 & 0.30 & 0.46 & 0.30 & 0.38 & 0.27 & 0.32 & 0.29 & 0.09 & 0.03 & 0.06 & 0.49 & 0.71 & 0.60 & 0.33 \\
\hline M06 & 0.26 & 0.30 & 0.28 & 1.11 & 0.69 & 0.90 & 0.26 & 0.32 & 0.29 & 0.20 & 0.17 & 0.19 & 0.26 & 0.60 & 0.43 & 0.42 \\
\hline M06-HF & 0.66 & 0.37 & 0.52 & 0.37 & 0.60 & 0.49 & 0.59 & 0.66 & 0.63 & 0.22 & 0.11 & 0.16 & 0.31 & 0.40 & 0.35 & 0.43 \\
\hline M05 & 0.58 & 0.53 & 0.55 & 0.68 & 0.30 & 0.49 & 0.23 & 0.24 & 0.23 & 0.14 & 0.06 & 0.10 & 1.12 & 1.34 & 1.23 & 0.52 \\
\hline M06-L & 0.21 & 0.51 & 0.36 & 1.80 & 1.41 & 1.61 & 0.32 & 0.32 & 0.32 & 0.19 & 0.13 & 0.16 & 0.17 & 0.42 & 0.29 & 0.55 \\
\hline PBEh & 0.40 & 0.28 & 0.34 & 1.04 & 0.75 & 0.90 & 0.35 & 0.38 & 0.37 & 0.12 & 0.18 & 0.15 & 1.84 & 2.09 & 1.96 & 0.74 \\
\hline B98 & 0.45 & 0.66 & 0.55 & 0.91 & 0.66 & 0.79 & 0.34 & 0.40 & 0.37 & 0.12 & 0.16 & 0.14 & 1.91 & 2.13 & 2.02 & 0.78 \\
\hline HFLYP & 1.50 & 1.08 & 1.29 & 0.88 & 1.02 & 0.95 & 0.22 & 0.31 & 0.26 & 0.15 & 0.05 & 0.10 & 1.28 & 1.53 & 1.41 & 0.80 \\
\hline TPSSh & 0.41 & 0.80 & 0.60 & 1.44 & 1.16 & 1.30 & 0.49 & 0.58 & 0.54 & 0.18 & 0.26 & 0.22 & 2.46 & 2.72 & 2.59 & 1.05 \\
\hline BMK & 0.68 & 0.96 & 0.82 & 0.41 & 0.62 & 0.52 & 0.78 & 0.97 & 0.88 & 0.76 & 0.85 & 0.81 & 2.36 & 2.57 & 2.47 & 1.10 \\
\hline B3LYP & 0.60 & 0.93 & 0.76 & 0.71 & 0.54 & 0.63 & 0.78 & 0.94 & 0.86 & 0.31 & 0.39 & 0.35 & 2.95 & 3.17 & 3.06 & 1.13 \\
\hline PBE & 0.45 & 0.32 & 0.39 & 2.95 & 2.63 & 2.79 & 0.46 & 0.40 & 0.43 & 0.13 & 0.15 & 0.14 & 1.86 & 2.09 & 1.97 & 1.14 \\
\hline B97-3 & 1.16 & 1.50 & 1.33 & 0.48 & 0.63 & 0.56 & 0.82 & 0.98 & 0.90 & 0.49 & 0.58 & 0.53 & 2.49 & 2.70 & 2.59 & 1.18 \\
\hline BLYP & 1.18 & 1.56 & 1.37 & 1.67 & 1.42 & 1.54 & 1.00 & 1.18 & 1.09 & 0.45 & 0.53 & 0.49 & 3.58 & 3.79 & 3.69 & 1.63 \\
\hline VSXC & 0.45 & 0.79 & 0.62 & 2.84 & 2.53 & 2.68 & 1.10 & 1.02 & 1.06 & 0.94 & 0.90 & 0.92 & 6.75 & 6.58 & 6.66 & 2.39 \\
\hline $\mathrm{HF}$ & 2.23 & 2.65 & 2.44 & 3.77 & 4.12 & 3.94 & 2.39 & 2.51 & 2.45 & 0.31 & 0.43 & 0.37 & 3.41 & 3.67 & 3.54 & 2.55 \\
\hline Average (DFT) & 0.62 & 0.69 & 0.65 & 1.13 & 0.97 & 1.05 & 0.52 & 0.58 & 0.55 & 0.29 & 0.29 & 0.29 & 1.88 & 2.08 & 1.98 & 0.90 \\
\hline Average (all) & 0.71 & 0.80 & 0.76 & 1.29 & 1.15 & 1.22 & 0.63 & 0.70 & 0.66 & 0.29 & 0.30 & 0.30 & 1.97 & 2.17 & 2.07 & 1.00 \\
\hline
\end{tabular}

The MG3S basis set is employed for all calculations. The MC-QCISD/3 geometries are used for the HB6, CT7, DI6, and WI7 databases; the geometries for benzene dimers in the PPS5 database are taken from Sinnokrot and Sherrill [64], and the geometries for the $\left(\mathrm{C}_{2} \mathrm{H}_{4}\right)_{2}$ and $\left(\mathrm{C}_{2} \mathrm{H}_{2}\right)_{2}$ dimers were optimized at the MC-QCISD/3 level of theory

MUE denotes mean unsigned error (MUE). MMUE $=[$ MUE(cp) + MUE(no-cp) $] / 2$, and MMMUE $=[M M U E(H B)+M M U E(C T)+M M U E(D I)$ + MMUE(WI) + MMUE(PPS) $] / 5 ; H B$ hydrogen bonding; $C T$ charge transfer; $D I$ dipole interaction; WI weak interaction; $P P S \pi-\pi$ stacking We use "no-cp" to denote calculation without counterpoise corrections for basis set superposition error (BSSE), and we use "cp" to denote calculations with counterpoise corrections for BSSE

MUEs are in Table 17. Table 17 shows that TPSSh, B98, B973, and M06 are the best performers for valence excitations, followed closely by several other functionals with mean unsigned error of $0.37 \mathrm{eV}$ or less. M05-2X, M06-2X, BMK, and M06-HF are the only functionals with mean unsigned errors below $0.78 \mathrm{eV}$ for Rydberg transitions. When valence and Rydberg transitions are combined in the VRES41 database, BMK, M05-2X, and M06-2X perform best. Although M06-HF is not as good as other high-quality density functionals for valence excitations, it is the best for long-range charge transfer excitation, and no other method gives useful results. In fact, the table shows that high Hartree-Fock exchange is not the entire reason for the success of M06-HF, since M06-HF is much better than either HF or HFLYP.

\subsection{Overall main group assessment}

In order to include electronic spectroscopy in our assessment we must use a weighted mean unsigned error since the mean unsigned errors in ES44 are an order of magnitude larger than those for TKNC294. We therefore normalize the errors by the average DFT errors, which are given in the second last rows of Tables 4-12 and 17. Furthermore TKNC306 is weighted three times higher than ES44 because, as indicated in Eq. (32), TKNC306 already corresponds to an average over three large databases. Thus we define a weighted mean unsigned error (WMUE) for 350 main group energetic data by

$$
\begin{aligned}
\text { WMUE }(\text { MGE350 })= & 0.75 \times \frac{\text { BMUE }(\text { TKNC306) }}{\text { Ave. }(\text { DFT, TKNC306) }} \\
& +0.25 \times \frac{\text { BMUE }(\text { ES44) }}{\text { Ave. }(\text { DFT, ES44) }}
\end{aligned}
$$

The results are given in Table 18. Notice that WMUE is unitless. Table 18 shows that when we include electronic excitation, M06-HF, M06-2X, and M05-2X are the most accurate functionals overall. The weights in Eq. (35) are clearly somewhat arbitrary, and some readers might want 
Table 11 Mean errors for the S22 noncovalent database of biological importance

\begin{tabular}{|c|c|c|c|c|}
\hline Method & $\begin{array}{l}\mathrm{JHB}^{\mathrm{a}} \\
\text { MMUE }\end{array}$ & $\begin{array}{l}\text { JDL }^{\mathrm{b}} \\
\text { MMUE }\end{array}$ & $\begin{array}{l}\mathrm{JM} 7^{\mathrm{c}} \\
\mathrm{MMUE}\end{array}$ & $\begin{array}{l}\mathrm{S} 22^{\mathrm{d}} \\
\text { BMMUE }\end{array}$ \\
\hline M06-2X & 0.73 & 0.36 & 0.32 & 0.47 \\
\hline M06-HF & 0.96 & 0.71 & 0.47 & 0.71 \\
\hline M05-2X & 0.80 & 1.01 & 0.43 & 0.75 \\
\hline M06-L & 0.82 & 0.76 & 0.72 & 0.77 \\
\hline M06 & 0.89 & 0.99 & 0.67 & 0.85 \\
\hline M05 & 1.26 & 3.16 & 1.09 & 1.83 \\
\hline HFLYP & 2.48 & 2.57 & 0.68 & 1.91 \\
\hline PBEh & 0.79 & 4.26 & 1.46 & 2.17 \\
\hline PBE & 1.13 & 4.53 & 1.66 & 2.44 \\
\hline B98 & 1.34 & 4.76 & 1.75 & 2.62 \\
\hline BMK & 1.86 & 3.95 & 2.06 & 2.62 \\
\hline TPSSh & 1.41 & 5.42 & 2.22 & 3.01 \\
\hline B3LYP & 1.77 & 6.22 & 2.64 & 3.54 \\
\hline B97-2 & 2.33 & 6.15 & 2.61 & 3.69 \\
\hline $\mathrm{HF}$ & 3.29 & 7.24 & 3.15 & 4.56 \\
\hline BLYP & 2.94 & 7.43 & 3.45 & 4.60 \\
\hline VSXC & 1.27 & 15.12 & 5.18 & 7.19 \\
\hline Average (DFT) & 1.42 & 4.21 & 1.71 & 2.45 \\
\hline Average (all) & 1.53 & 4.39 & 1.80 & 2.57 \\
\hline
\end{tabular}

a Seven hydrogen bonded complexes from the S22 database of Jurecka et al. [65]

${ }^{\mathrm{b}}$ Eight complexes dominated by dispersion-like interactions, including $\pi-\pi$ stacking from the S22 database of Jurecka et al. [65]

${ }^{c}$ Seven mixed complexes, e.g., benzene $\cdots \mathrm{H}_{2} \mathrm{O}$ from the $\mathrm{S} 22$ database of Jurecka et al. [65]

d Average of the previous columns. Each column is weighted one-third to balance the contributions of the three component database

to recompute the last column with a higher weight on ES44. Since the three highest ranked functionals for the weighted average are also the three highest ranked functionals for ES44, they would still be at the top of the table if we used any higher weighting for ES44.

\subsection{Transition element bond energies}

Transition-element metal-metal and metal-ligand bonding is very important in many application areas [97,131-147], but we have shown $[14,38,39]$ that functionals with a high percentage of HF exchange are not suitable for the prediction of metal-metal and metal-ligand bonding in transition-metalcontaining molecules with unsaturated valences, apparently in large part due to the multireference character of open-shell transition-metal species. In Table 19, we give the results of the TMRE48 database only for the 14 functionals that do not have full HF exchange.
Table 12 Assessment of functionals for thermochemistry, kinetics, and noncovalent interactions

\begin{tabular}{lclclc}
\hline Method & $\begin{array}{l}\text { TC177 } \\
\text { MUE }\end{array}$ & $\begin{array}{l}\text { DBH76 } \\
\text { BMUE }\end{array}$ & $\begin{array}{l}\text { TK253 } \\
\text { BMUE }\end{array}$ & $\begin{array}{l}\text { NCIE53 } \\
\text { BMUE }\end{array}$ & $\begin{array}{l}\text { TKNC306 } \\
\text { BMUE }\end{array}$ \\
\hline M06-2X & 1.32 & 1.22 & 1.27 & 0.37 & 0.97 \\
M05-2X & 1.63 & 1.65 & 1.64 & 0.54 & 1.27 \\
M06 & 1.82 & 2.21 & 2.02 & 0.63 & 1.56 \\
BMK & 1.80 & 1.32 & 1.56 & 1.86 & 1.66 \\
M06-HF & 2.29 & 2.38 & 2.33 & 0.57 & 1.75 \\
M05 & 2.57 & 2.19 & 2.38 & 1.18 & 1.98 \\
B97-3 & 2.80 & 1.72 & 2.26 & 2.44 & 2.32 \\
M06-L & 2.94 & 3.88 & 3.41 & 0.66 & 2.49 \\
B98 & 2.59 & 3.57 & 3.08 & 1.70 & 2.62 \\
PBEh & 2.89 & 3.76 & 3.33 & 1.46 & 2.71 \\
B3LYP & 3.59 & 4.50 & 4.04 & 2.34 & 3.47 \\
TPSSh & 3.23 & 6.62 & 4.93 & 2.03 & 3.96 \\
VSXC & 3.00 & 5.00 & 4.00 & 4.79 & 4.27 \\
PBE & 5.20 & 8.64 & 6.92 & 1.79 & 5.21 \\
BLYP & 4.80 & 8.52 & 6.66 & 3.12 & 5.48 \\
HFLYP & 12.73 & 7.01 & 9.87 & 1.36 & 7.03 \\
HF & 39.18 & 8.41 & 23.79 & 3.55 & 17.05 \\
Average (DFT) & 3.45 & 4.01 & 3.73 & 1.68 & 3.05 \\
Average (all) & 5.55 & 4.27 & 4.91 & 1.79 & 3.87 \\
\hline
\end{tabular}

The MUE for TC177 and the BMUEs for TK253, NCIE53, and TKNC306 are defined in Eqs. (29), (30), (31), and (32). BMUEs for the DBH76 database are from Table 9

The TMRE48 transition metal bonding database consists of the TMAE9 [38] set of 9 transition metal-metal bond energies, the MLBE21 [39] database of 21 metal-ligand bond energies, and the $3 d$ TMRE18 $[43,76]$ benchmark database of 18 reaction energies involving $3 d$ transition metals. Table 19 summarizes the mean errors for these databases. For the TMAE9 database of bond energies of transition metal dimers, M06, M06-L, and BLYP give the best results. For the MLBE21 database of metal-ligand bond energies, M06, M06-L, M05, and TPSSh give the best performance, and M06, M06-L, and M05 perform best for the 3dTMRE18 database.

In Table 19, the BMUE(TMRE48) is the average of the MUE for the TMAE9, MLBE21, and 3dTMRE18 databases, and M06-L, M06, and M05 give the smallest BMUE. Thus these are the three strongly recommended methods for transition-metal chemistry.

\subsection{Metal atom excitation energy}

MAEE5 [16] is a database of five metal-atom excitation energies containing two main group neutral metals $(\mathrm{Be}, \mathrm{Mg})$, two neutral transition metals (Mn, Pd), and one transition 
Table 13 Excitation energies (eV) for $\mathrm{N}_{2}$

\begin{tabular}{|c|c|c|c|c|c|c|c|c|c|c|c|c|c|}
\hline \multirow{2}{*}{$\begin{array}{l}\text { Type } \\
\text { State } \\
\text { Transition }\end{array}$} & \multicolumn{5}{|l|}{ Rydberg } & \multicolumn{8}{|l|}{ Valence } \\
\hline & ${ }^{1} \prod_{\mathrm{u}}$ & $\begin{array}{c}{ }^{1} \sum_{\mathrm{u}}^{+} \\
\sigma_{g} \rightarrow 3 p \sigma_{u}\end{array}$ & $\begin{array}{l}{ }^{1} \prod_{\mathrm{u}} \\
\sigma_{g} \rightarrow 3 p \pi_{u}\end{array}$ & ${ }_{{ }^{1} \sum_{g}^{+} \rightarrow 3 s \sigma_{g}}^{+}$ & $\begin{array}{l}{ }^{3} \sum_{g}^{+} \\
\sigma_{g} \rightarrow 3 s \sigma_{g}\end{array}$ & $\begin{array}{l}{ }^{3} \prod_{\mathrm{u}} \\
\sigma_{u} \rightarrow \pi_{g}\end{array}$ & $\begin{array}{l}{ }^{1} \Delta_{\mathrm{u}} \\
\pi_{u} \rightarrow \pi_{g}\end{array}$ & ${ }^{1} \sum_{\mathrm{u}}^{-}$ & $\begin{array}{l}{ }^{3} \sum_{\mathrm{u}}^{-} \\
\pi_{u} \rightarrow \pi_{g}\end{array}$ & $\begin{array}{l}{ }^{1} \prod_{\mathrm{g}} \\
\sigma_{g} \rightarrow \pi_{g}\end{array}$ & $\begin{array}{l}{ }^{3} \Delta_{\mathrm{u}} \\
\pi_{u} \rightarrow \pi_{g}\end{array}$ & $\begin{array}{l}{ }^{3} \prod_{\mathrm{g}} \\
\sigma_{g} \rightarrow \pi_{g}\end{array}$ & $\begin{array}{l}{ }^{3} \sum_{\mathrm{u}}^{+} \\
\pi_{u} \rightarrow \pi_{g}\end{array}$ \\
\hline Accurate $^{\mathrm{a}}$ & 13.24 & 12.98 & 12.90 & 12.20 & 12.00 & 11.19 & 10.27 & 9.92 & 9.67 & 9.31 & 8.88 & 8.04 & 7.75 \\
\hline B3LYP & 12.04 & 11.62 & 11.78 & 11.24 & 10.99 & 10.63 & 9.72 & 9.31 & 9.31 & 9.24 & 7.97 & 7.55 & 7.06 \\
\hline B97-3 & 12.33 & 11.96 & 12.10 & 11.59 & 11.30 & 11.00 & 9.80 & 9.28 & 9.28 & 9.34 & 8.17 & 7.74 & 7.22 \\
\hline B98 & 12.20 & 11.81 & 11.97 & 11.44 & 11.15 & 10.85 & 9.75 & 9.32 & 9.32 & 9.30 & 8.10 & 7.69 & 7.07 \\
\hline BLYP & 11.29 & 10.34 & 10.72 & 10.11 & 9.98 & 10.31 & 9.85 & 9.55 & 9.55 & 9.06 & 8.22 & 7.41 & 7.44 \\
\hline BMK & 12.72 & 12.60 & 12.59 & 12.19 & 11.92 & 11.30 & 9.92 & 8.85 & 8.85 & 9.28 & 8.39 & 7.76 & 7.27 \\
\hline $\mathrm{HF}$ & 14.05 & 14.83 & 13.21 & 13.98 & 13.05 & 11.28 & 8.77 & 7.93 & 7.93 & 9.77 & 7.62 & 5.85 & 3.45 \\
\hline HFLYP & 14.77 & 14.95 & 13.82 & 14.60 & 13.80 & 11.58 & 9.77 & 7.92 & 7.92 & 8.83 & 7.81 & 6.29 & 4.62 \\
\hline M05 & 12.39 & 11.43 & 11.54 & 11.01 & 10.62 & 10.99 & 9.78 & 9.09 & 9.09 & 8.89 & 8.23 & 7.57 & 6.93 \\
\hline M05-2X & 13.36 & 13.16 & 13.16 & 12.75 & 12.32 & 11.10 & 10.19 & 8.35 & 8.35 & 9.15 & 8.82 & 7.63 & 7.24 \\
\hline M06-HF & 13.48 & 13.40 & 12.45 & 12.99 & 12.06 & 11.25 & 10.20 & 6.47 & 6.47 & 8.71 & 9.51 & 7.55 & 7.53 \\
\hline M06-L & 11.78 & 10.72 & 11.10 & 10.50 & 10.24 & 11.14 & 9.87 & 10.25 & 10.25 & 9.42 & 8.06 & 7.86 & 7.33 \\
\hline M06 & 11.54 & 11.05 & 10.95 & 10.41 & 10.11 & 10.83 & 9.33 & 9.08 & 9.08 & 8.94 & 8.11 & 7.73 & 7.05 \\
\hline M06-2X & 12.55 & 12.60 & 12.51 & 12.01 & 11.68 & 11.33 & 9.96 & 8.41 & 8.41 & 9.05 & 8.84 & 7.74 & 7.48 \\
\hline PBE & 11.47 & 10.48 & 10.80 & 10.23 & 10.06 & 10.38 & 10.08 & 9.66 & 9.66 & 9.08 & 8.31 & 7.37 & 7.51 \\
\hline PBEh & 12.32 & 11.87 & 11.99 & 11.47 & 11.17 & 10.74 & 9.89 & 9.34 & 9.34 & 9.31 & 7.90 & 7.50 & 6.93 \\
\hline TPSSh & 11.91 & 11.20 & 11.46 & 10.90 & 10.72 & 10.75 & 9.94 & 9.72 & 9.72 & 9.32 & 7.97 & 7.48 & 7.03 \\
\hline VSXC & 11.79 & 10.75 & 11.25 & 10.58 & 10.43 & 10.78 & 10.14 & 10.01 & 10.01 & 9.39 & 8.41 & 7.71 & 7.25 \\
\hline
\end{tabular}

The augmented Sadlej pVTZ basis set [72,73] and experimental geometry $\left(r_{\mathrm{N}-\mathrm{N}}=1.098 \AA\right)$ were employed for all TDDFT calculations

a The accurate data for $\mathrm{N}_{2}$ were taken from an experimental study [126]

Table 14 Excitation energies (eV) for $\mathrm{CO}$

\begin{tabular}{|c|c|c|c|c|c|c|c|c|c|c|c|c|c|c|}
\hline \multirow{2}{*}{$\begin{array}{l}\text { Type } \\
\text { State } \\
\text { Transition }\end{array}$} & \multicolumn{5}{|l|}{ Rydberg } & \multicolumn{9}{|c|}{ Valence } \\
\hline & ${ }_{\sigma \rightarrow 3 d \sigma}^{+}$ & $\prod_{\sigma \rightarrow 3 p \pi}$ & $\prod_{\sigma \rightarrow 3 p \pi}^{3}$ & $\sum_{\sigma \rightarrow 3 p \sigma}^{+}$ & ${ }_{\sigma \rightarrow 3 p \sigma}^{3}$ & ${ }_{\sigma \rightarrow 3 s}^{1}$ & $\sum_{\sigma \rightarrow 3 s}^{+}$ & ${ }_{\pi \rightarrow \pi^{*}}{ }^{*}$ & ${ }_{\pi \rightarrow \pi^{1}}^{-}$ & ${ }_{\pi \rightarrow \pi^{3}} \sum^{-}$ & $\begin{array}{l}{ }^{3} \Delta \\
\pi \rightarrow \pi^{*}\end{array}$ & $\prod_{\sigma \rightarrow \pi^{*}}$ & ${ }_{\pi \rightarrow \pi^{3}} \sum^{+}$ & $\prod_{\sigma \rightarrow \pi^{3}}$ \\
\hline Accurate $^{\mathrm{a}}$ & 12.40 & 11.53 & 11.55 & 11.40 & 11.30 & 10.78 & 10.40 & 10.23 & 9.88 & 9.88 & 9.36 & 8.51 & 8.51 & 6.32 \\
\hline B3LYP & 10.47 & 10.27 & 10.24 & 10.21 & 10.19 & 9.83 & 9.56 & 10.04 & 9.71 & 9.71 & 8.64 & 8.40 & 7.92 & 5.85 \\
\hline B97-3 & 10.75 & 10.55 & 10.43 & 10.50 & 10.37 & 10.13 & 9.80 & 10.16 & 9.75 & 9.75 & 8.86 & 8.47 & 8.10 & 6.09 \\
\hline B98 & 10.59 & 10.45 & 10.35 & 10.38 & 10.29 & 10.02 & 9.68 & 10.11 & 9.76 & 9.76 & 8.79 & 8.46 & 7.99 & 6.04 \\
\hline BLYP & 9.69 & 9.62 & 9.64 & 9.36 & 9.22 & 8.81 & 8.69 & 10.00 & 9.75 & 9.75 & 8.67 & 8.24 & 8.06 & 5.81 \\
\hline BMK & 11.38 & 10.99 & 10.90 & 10.95 & 10.86 & 10.55 & 10.23 & 10.37 & 9.55 & 9.55 & 9.11 & 8.45 & 8.25 & 6.15 \\
\hline $\mathrm{HF}$ & 13.55 & 12.59 & 12.37 & 12.56 & 12.28 & 11.88 & 10.96 & 9.96 & 9.38 & 9.38 & 7.88 & 8.80 & 6.34 & 5.28 \\
\hline HFLYP & 14.24 & 13.26 & 13.02 & 13.16 & 12.94 & 12.48 & 11.70 & 10.07 & 9.43 & 9.43 & 8.25 & 8.80 & 7.10 & 5.69 \\
\hline M05 & 10.44 & 10.25 & 10.10 & 10.19 & 10.06 & 9.80 & 9.32 & 10.16 & 9.64 & 9.64 & 8.94 & 8.18 & 7.84 & 5.97 \\
\hline M05-2X & 11.99 & 11.61 & 11.46 & 11.53 & 11.41 & 11.09 & 10.62 & 10.35 & 9.13 & 9.13 & 9.12 & 8.30 & 7.98 & 6.04 \\
\hline M06-HF & 12.99 & 11.62 & 11.28 & 11.68 & 11.24 & 10.98 & 9.83 & 10.18 & 7.61 & 7.61 & 9.45 & 7.91 & 8.00 & 6.19 \\
\hline M06-L & 9.84 & 9.83 & 9.62 & 9.63 & 9.53 & 9.35 & 9.03 & 10.28 & 10.49 & 10.49 & 8.92 & 8.59 & 8.04 & 6.16 \\
\hline M06 & 10.44 & 9.70 & 9.55 & 9.70 & 9.52 & 9.11 & 8.80 & 9.88 & 9.60 & 9.60 & 9.01 & 8.18 & 8.03 & 6.19 \\
\hline M06-2X & 11.70 & 10.99 & 10.91 & 10.92 & 10.83 & 10.44 & 10.08 & 10.23 & 9.13 & 9.13 & 9.27 & 8.22 & 8.15 & 6.25 \\
\hline PBE & 9.48 & 9.42 & 9.36 & 9.27 & 9.24 & 8.98 & 8.79 & 10.18 & 9.84 & 9.84 & 8.74 & 8.25 & 8.09 & 5.73 \\
\hline PBEh & 10.68 & 10.49 & 10.42 & 10.42 & 10.35 & 10.05 & 9.70 & 10.20 & 9.78 & 9.78 & 8.61 & 8.44 & 7.84 & 5.73 \\
\hline TPSSh & 10.14 & 10.06 & 10.01 & 9.96 & 9.93 & 9.64 & 9.43 & 10.17 & 10.01 & 10.01 & 8.61 & 8.52 & 7.87 & 5.77 \\
\hline VSXC & 9.81 & 9.79 & 9.73 & 9.50 & 9.53 & 9.34 & 9.19 & 10.30 & 10.18 & 10.18 & 8.89 & 8.56 & 7.95 & 6.05 \\
\hline
\end{tabular}

The augmented Sadlej pVTZ basis set [72,73] and experimental geometry $\left(r_{\mathrm{C}-\mathrm{O}}=1.128 \AA\right)$ were employed for all TDDFT calculations

${ }^{a}$ The accurate data for $\mathrm{CO}$ were taken from an experimental study [127] 
Table 15 Excitation energies (eV) for $\mathrm{HCHO}$

\begin{tabular}{|c|c|c|c|c|c|c|c|c|c|c|c|c|}
\hline \multirow{2}{*}{$\begin{array}{l}\text { Type } \\
\text { State } \\
\text { Transition }\end{array}$} & \multicolumn{8}{|l|}{ Rydberg } & \multicolumn{4}{|l|}{ Valence } \\
\hline & $\begin{array}{l}{ }^{1} A_{2} \\
n \rightarrow 3 d b_{1}\end{array}$ & $\begin{array}{l}{ }^{1} A_{2} \\
n \rightarrow 3 d b_{1}\end{array}$ & $\begin{array}{l}{ }^{1} B_{2} \\
n \rightarrow 3 p a_{1}\end{array}$ & $\begin{array}{l}{ }^{3} B_{2} \\
n \rightarrow 3 p a_{1}\end{array}$ & $\begin{array}{l}{ }^{1} A_{1} \\
n \rightarrow 3 p b_{2}\end{array}$ & $\begin{array}{l}{ }^{3} A_{1} \\
n \rightarrow 3 p b_{2}\end{array}$ & $\begin{array}{l}{ }^{1} B_{2} \\
n \rightarrow 3 s a_{1}\end{array}$ & $\begin{array}{l}{ }^{3} B_{2} \\
n \rightarrow 3 s a_{1}\end{array}$ & $\begin{array}{l}{ }^{1} B_{1} \\
\sigma \rightarrow \pi *\end{array}$ & $\begin{array}{l}{ }^{3} A_{1} \\
\pi \rightarrow \pi *\end{array}$ & $\begin{array}{l}{ }^{1} A_{2} \\
n \rightarrow \pi *\end{array}$ & $\begin{array}{l}{ }^{3} A_{2} \\
n \rightarrow \pi *\end{array}$ \\
\hline Accurate $^{a}$ & 9.22 & 8.38 & 8.12 & 7.96 & 7.97 & 7.79 & 7.09 & 6.83 & 8.68 & 5.53 & 3.94 & 3.50 \\
\hline B3LYP & 7.94 & 7.35 & 7.16 & 7.10 & 7.15 & 7.10 & 6.43 & 6.32 & 9.03 & 5.48 & 3.92 & 3.20 \\
\hline B97-3 & 8.16 & 7.60 & 7.45 & 7.34 & 7.45 & 7.32 & 6.81 & 6.68 & 9.17 & 5.66 & 4.00 & 3.32 \\
\hline B98 & 8.04 & 7.48 & 7.32 & 7.23 & 7.31 & 7.21 & 6.62 & 6.47 & 9.09 & 5.59 & 3.96 & 3.28 \\
\hline BLYP & 6.91 & 6.35 & 6.21 & 6.20 & 6.16 & 6.15 & 5.61 & 5.52 & 8.82 & 5.81 & 3.82 & 3.12 \\
\hline BMK & 8.59 & 7.97 & 7.82 & 7.72 & 7.67 & 7.58 & 7.19 & 7.06 & 9.08 & 5.83 & 3.90 & 3.24 \\
\hline $\mathrm{HF}$ & 11.22 & 9.69 & 9.28 & 8.93 & 9.52 & 9.18 & 8.54 & 8.13 & 9.71 & 2.21 & 4.42 & 3.45 \\
\hline HFLYP & 11.11 & 10.37 & 9.78 & 9.45 & 9.43 & 9.83 & 9.03 & 8.68 & 9.75 & 3.39 & 4.42 & 3.54 \\
\hline M05 & 7.98 & 7.36 & 7.17 & 7.03 & 7.18 & 6.99 & 6.41 & 6.18 & 8.37 & 5.46 & 3.83 & 3.29 \\
\hline M05-2X & 9.40 & 8.76 & 8.41 & 8.26 & 8.54 & 8.41 & 7.68 & 7.58 & 9.00 & 5.49 & 3.72 & 3.11 \\
\hline M06-HF & 9.87 & 8.86 & 8.44 & 8.01 & 8.71 & 8.33 & 7.69 & 7.25 & 8.50 & 5.74 & 3.16 & 2.72 \\
\hline M06-L & 7.49 & 6.93 & 6.65 & 6.64 & 6.68 & 6.54 & 6.29 & 6.03 & 9.38 & 5.82 & 4.31 & 3.65 \\
\hline M06 & 7.85 & 6.83 & 6.61 & 6.48 & 6.64 & 6.45 & 5.92 & 5.72 & 8.83 & 5.72 & 3.85 & 3.41 \\
\hline M06-2X & 9.08 & 8.16 & 7.85 & 7.73 & 7.98 & 7.89 & 7.14 & 7.06 & 8.90 & 5.82 & 3.70 & 3.18 \\
\hline PBE & 7.00 & 6.46 & 6.30 & 6.29 & 6.27 & 6.24 & 5.73 & 5.59 & 8.91 & 5.81 & 3.80 & 3.06 \\
\hline PBEh & 8.12 & 7.54 & 7.37 & 7.27 & 7.37 & 7.28 & 6.67 & 6.49 & 8.90 & 5.29 & 3.94 & 3.15 \\
\hline TPSSh & 7.57 & 7.03 & 6.93 & 6.89 & 6.87 & 6.84 & 6.29 & 6.17 & 9.14 & 5.43 & 4.08 & 3.26 \\
\hline VSXC & 7.26 & 6.73 & 6.45 & 6.44 & 6.48 & 6.47 & 6.09 & 5.91 & 9.31 & 5.68 & 4.06 & 3.36 \\
\hline
\end{tabular}

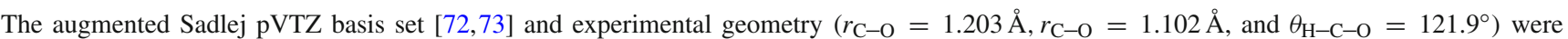
employed for all TDDFT calculations

a The accurate data for HCHO were taken from a experimental study [128]

metal cation $\left(\mathrm{Cu}^{+}\right)$. Table 20 presents the performance for the MAEE5 database of excitation energies of metal atoms. We give the performance of all functionals that do not have full $\mathrm{HF}$ exchange. Note that the excitation energies in this section are calculated by the $\triangle \mathrm{SCF}$ approach rather than TDDFT. Among the tested DFT methods, VSXC, B98, M06-L, and M06 give the best performance, whereas BMK gives poor results for this database.

\subsection{Overall assessment of energetics}

For an overall assessment of energetics, we average the mean unsigned error in main group energetics in reduced units (that is, divided by the average error of all DFT methods tested) and the mean unsigned error in transition metal energetics, also in reduced units. The resulting overall assessment is in the last column of Table 21. More specifically, the new quantities in Table 21, BMUE(TME53) are defined by

$$
\begin{aligned}
\operatorname{BMUE}(\text { TME53 })= & 0.75 \times \text { AMUE }(\text { TMRE48) } \\
& +0.25 \times \text { MUE }(\text { MAEE5 })
\end{aligned}
$$

where AMUE(TMRE48) is the average of three databases in Table 19 and MUE(MAEE5) is from Table 20 and by

$$
\begin{aligned}
\text { WMUE }(\text { M06E403 })= & 0.5 \times \frac{\text { WMUE }(\text { MGE350) }}{\text { Ave. }(\text { DFT, MGE350) }} \\
& +0.5 \times \frac{\text { BMUE(TME53) }}{\text { Ave. }(\text { DFT, TME53) }}
\end{aligned}
$$

Note that even though only three of the five data in MAEE5 are for transition elements, we average it with TMRE48 although it is weighted only $25 \%$. Table 21 summarizes our complete energetic assessment, and it shows that M06, M05, and M06-L are the best performing functionals for the 403 energetic data in the present study.

Another way to measure the success of a functional is by its applicability to a wide variety of problems. We therefore counted the number of times that each functional appears among the top four functionals in the 13 previous tables that have mean errors in the last column (Tables 4-12 and 17-20). M06-2X appears 11 times; M05-2X appears 10 times; M06, 9 times; BMK and M06-HF, 6 times; M06-L, 4 times; and no other functional more than twice. The broad generality of these functionals provides a motivation for future work that would attempt to obtain more physical insight by analyzing 
Table 16 Excitation energies $(\mathrm{eV})$ for tetracene, $\mathrm{NH}_{3} \cdots \mathrm{F}_{2}$, and $\mathrm{C}_{2} \mathrm{H}_{4} \cdots \mathrm{C}_{2} \mathrm{~F}_{4}$

\begin{tabular}{|c|c|c|c|c|}
\hline \multirow{2}{*}{$\begin{array}{l}\text { Molecule } \\
\text { Type } \\
\text { State } \\
\text { Transition }\end{array}$} & \multicolumn{2}{|c|}{ Tetraacene } & \multirow{2}{*}{$\begin{array}{l}\mathrm{NH}_{3} \cdots \mathrm{F}_{2} \\
\mathrm{CT} \\
{ }^{3} A_{1} \\
n \rightarrow \sigma^{*}\end{array}$} & \multirow{2}{*}{$\begin{array}{l}\mathrm{C}_{2} \mathrm{H}_{4} \cdots \mathrm{C}_{2} \mathrm{~F}_{4} \\
\mathrm{CT} \\
{ }^{3} B_{2} \\
\pi \rightarrow \pi^{*}\end{array}$} \\
\hline & $\begin{array}{l}\text { Valence } \\
B_{2 \mathrm{u}} \\
\mathrm{L}_{\mathrm{a}}\end{array}$ & $\begin{array}{l}\mathrm{CT} \\
B_{3 \mathrm{u}} \\
\mathrm{L}_{\mathrm{b}}\end{array}$ & & \\
\hline Best estimate $^{\mathrm{a}}$ & 3.4 & 2.9 & 9.5 & 12.6 \\
\hline B3LYP & 3.4 & 2.4 & 2.2 & 7.0 \\
\hline M05-2X & 3.7 & 2.7 & 5.4 & 9.6 \\
\hline M06-2X & 3.7 & 2.8 & 5.5 & 9.4 \\
\hline PBEh & 3.5 & 2.5 & 2.8 & 7.4 \\
\hline M05 & 3.5 & 2.5 & 2.6 & 7.6 \\
\hline TPSSh & 3.4 & 2.3 & 1.5 & 6.4 \\
\hline BMK & 3.7 & 2.7 & 4.3 & 8.7 \\
\hline M06-HF & 3.8 & 3.0 & 9.4 & 12.6 \\
\hline $\mathrm{HF}$ & 3.9 & 2.9 & 11.1 & 13.9 \\
\hline B98 & 3.5 & 2.4 & 2.6 & 7.2 \\
\hline B97-3 & 3.5 & 2.5 & 3.0 & 7.6 \\
\hline M06 & 3.4 & 2.4 & 2.6 & 7.6 \\
\hline HFLYP & 3.9 & 3.0 & 11.0 & 14.1 \\
\hline M06-L & 3.2 & 2.2 & 0.8 & 5.7 \\
\hline BLYP & 3.0 & 2.1 & 0.1 & 5.2 \\
\hline VSXC & 3.1 & 2.2 & 0.3 & 5.6 \\
\hline PBE & 3.0 & 2.1 & 0.1 & 5.1 \\
\hline
\end{tabular}

The 6-31+G(d,p) basis set was employed for the calculations of $\mathrm{NH}_{3} \cdots \mathrm{F}_{2}$; the 6-31G* basis set was employed for the $\mathrm{C}_{2} \mathrm{H}_{4} \cdots \mathrm{C}_{2} \mathrm{~F}_{4}$ complex, and the 6-311G(2d,p) basis set was employed for tetracene

${ }^{a}$ The accurate data for tetraacene were taken from experiment [129] as given by Grimme and Parac [130]; the accurate charge transfer excitaion energy for $\mathrm{C}_{2} \mathrm{H}_{4} \cdots \mathrm{C}_{2} \mathrm{~F}_{4}$ was taken from a previous paper by Tawada et al. [125], and the charge transfer excitation energy for the $\mathrm{NH}_{3} \cdots \mathrm{F}_{2}$ complex was calculated at the SAC-CI/6-31+G(d,p) level of theory [19]

the functionals themselves. It also provides a validation for using these functionals in the kinds of applications for which they are successful.

\section{Geometries and scaling factors for the prediction of harmonic frequencies and zero-point vibrational energies}

It is also important to evaluate the performance of the developed DFT models for the prediction of properties other than energetic data. In this section we discuss performance for the calculation of bond lengths, harmonic frequencies, and zero-point vibrational energies (ZPVEs).

Table 22 presents the mean errors for the prediction of equilibrium bond lengths in the MGBL19 database [16], MLBL13 database [39], and TMBL8 database [38].
Table 17 Errors (eV) for electronic spectroscopy

\begin{tabular}{llllll}
\hline Method & $\begin{array}{l}\text { VES21 } \\
\text { MUE }\end{array}$ & $\begin{array}{l}\text { RES20 } \\
\text { MUE }\end{array}$ & $\begin{array}{l}\text { VRES41 }^{\text {MUE }} \\
\text { M06-HF }\end{array}$ & $\begin{array}{l}\text { CTE3 } \\
\text { MUE }\end{array}$ & $\begin{array}{l}\text { ES44 } \\
\text { BMUE }^{b}\end{array}$ \\
M05-2X & 0.71 & 0.39 & 0.55 & 0.09 & 0.40 \\
M06-2X & 0.34 & 0.31 & 0.34 & 2.42 & 1.03 \\
HF & 1.08 & 1.18 & 1.13 & 0.99 & 1.08 \\
HFLYP & 0.87 & 1.72 & 1.28 & 1.01 & 1.20 \\
BMK & 0.30 & 0.35 & 0.33 & 3.10 & 1.25 \\
B97-3 & 0.25 & 0.78 & 0.51 & 3.94 & 1.66 \\
PBEh & 0.29 & 0.86 & 0.57 & 4.08 & 1.75 \\
B98 & 0.24 & 0.92 & 0.57 & 4.25 & 1.80 \\
M05 & 0.29 & 1.16 & 0.71 & 4.12 & 1.85 \\
B3LYP & 0.28 & 1.07 & 0.66 & 4.44 & 1.93 \\
M06 & 0.27 & 1.67 & 0.95 & 4.11 & 2.02 \\
TPSSh & 0.24 & 1.33 & 0.77 & 4.93 & 2.17 \\
M06-L & 0.32 & 1.62 & 0.95 & 5.44 & 2.46 \\
VSXC & 0.27 & 1.64 & 0.94 & 5.63 & 2.52 \\
PBE & 0.32 & 1.95 & 1.12 & 5.86 & 2.71 \\
BLYP & 0.35 & 2.00 & 1.16 & 5.85 & 2.74 \\
Average (DFT) & 0.36 & 1.13 & 0.74 & 3.86 & 1.78 \\
Average (all) & 0.40 & 1.13 & 0.76 & 3.69 & 1.74 \\
\hline a & 0.95 (VRES41 & & & \\
\hline
\end{tabular}

${ }^{\mathrm{a}}$ MUE $(\operatorname{VRES} 41)=[21 \mathrm{MUE}(\operatorname{VES} 21)+20 \mathrm{MUE}(\mathrm{RES} 20)] / 41$

${ }^{\mathrm{b}} \mathrm{BMUE}(\mathrm{ES} 44)=(\operatorname{MUE}(\operatorname{VES} 21)+\operatorname{MUE}(\operatorname{RES} 20)+\operatorname{MUE}(\mathrm{CTES} 3)) / 3$. Note that the balanced MUE (BMUE) weights each category of excited state equally to balance the contributions of the three component databases

MGBL19 is database of 19 bond lengths of 15 main-group molecules, MLBL13 is a database of 13 bond lengths of 13 transition metal-ligand compounds, and TMBL8 is a database of 8 metal-metal bond lengths in 8 transition metal dimers. Table 22 shows that VSXC, M06-L, and TPSSh give the best performance for the MGBL19 database, PBE, TPSSh, and B3LYP perform best for the MLBL13 database, and PBE, BLYP, and TPSSh give the best performance for the TMBL8 database. We also tabulated another MUE, labeled TMBL7, which excludes the $\mathrm{Cr}_{2}$ dimer, because it is a difficult case for most of the tested functionals and therefore it can dominate the error when included. If we exclude the $\mathrm{Cr}_{2}$ dimer, PBE VSXC, and BLYP are the best functionals, followed by the M06-L and TPSSh methods. Overall PBE, TPSSh, BLYP, and M06-L are the four best functionals for the prediction of bond lengths in these three databases, as shown by their low BMUE for the whole set of 40 molecules.

It is customary to use a scaling factor to calculate vibrational frequencies, ZPVEs, and thermal vibrational contributions to enthalpies and free energies. Such scaling factor may be optimized in various ways [148-150], and it is important 
Table 18 Overall assessment for main group energetics

\begin{tabular}{|c|c|c|c|}
\hline \multirow[t]{2}{*}{ Method } & \multirow{2}{*}{ 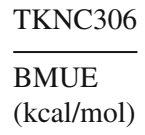 } & \multirow{2}{*}{$\frac{\mathrm{ES} 44}{\mathrm{BMUE}(\mathrm{eV})}$} & \multirow{2}{*}{$\begin{array}{l}\text { MGE350 } \\
\text { WMUE } \\
\text { (reduced units) }\end{array}$} \\
\hline & & & \\
\hline M06-2X & 0.97 & 1.05 & 0.39 \\
\hline M05-2X & 1.27 & 1.03 & 0.46 \\
\hline M06-HF & 1.75 & 0.40 & 0.49 \\
\hline BMK & 1.66 & 1.25 & 0.58 \\
\hline M06 & 1.56 & 2.02 & 0.67 \\
\hline M05 & 1.98 & 1.85 & 0.75 \\
\hline B97-3 & 2.32 & 1.66 & 0.80 \\
\hline B98 & 2.62 & 1.80 & 0.90 \\
\hline PBEh & 2.71 & 1.75 & 0.91 \\
\hline M06-L & 2.49 & 2.46 & 0.96 \\
\hline B3LYP & 3.47 & 1.93 & 1.13 \\
\hline TPSSh & 3.96 & 2.17 & 1.28 \\
\hline VSXC & 4.27 & 2.52 & 1.40 \\
\hline PBE & 5.21 & 2.71 & 1.66 \\
\hline BLYP & 5.48 & 2.74 & 1.73 \\
\hline HFLYP & 7.03 & 1.20 & 1.90 \\
\hline $\mathrm{HF}$ & 17.05 & 1.08 & 4.35 \\
\hline Average (DFT) & 3.05 & 1.78 & 1.00 \\
\hline Average (all) & 3.87 & 1.74 & 1.20 \\
\hline
\end{tabular}

WMUE $($ MGE350 $)=0.75 \times \frac{\text { BMUE(TKNC306) }}{\text { Ave.(DFT,TKNC306) }}+0.25 \times$ BMUE (ES44)

Ave.(DFT,ES44)

to keep in mind that there is more than one kind of vibrational frequency in the literature. Harmonic vibrational frequencies (also called [151] "vibrational frequencies for infinitesimal amplitudes") are obtained computationally from the Hessian at the equilibrium geometry or experimentally by extrapolating a vibrational progression to the experimentally inaccessible vibrationless state. The full set of harmonic vibrational frequencies is usually unavailable for polyatomic molecules since their determination requires an elaborate analysis of anharmonicity; therefore one often deals with the observed fundamental frequencies, which include both principal (intramode) anharmonicity and mode-mode coupling. This same analysis yields an estimate of the true ZPVE. In the present article, all frequencies are harmonic frequencies, and all test data for ZPVEs are best estimates of true ZPVEs, not harmonic ZPVEs. However calculated ZPVEs are simply computed as one half the sum of the frequencies. To optimize scaling factors for harmonic frequencies, we employed the F38/06 database, which consists of the F36/06 database [16] plus the harmonic frequencies [152] of the $\mathrm{OH}$ and $\mathrm{Cl}_{2}$ molecules. For the optimizations of scaling factors for ZPVE, we employed the ZPVE15/06 database, which consists of the ZPVE13/99 [6,150] database plus the ZPVEs [152] of $\mathrm{OH}$ and $\mathrm{Cl}_{2}$. Table 23 gives the data [152] that we used for $\mathrm{OH}$ and $\mathrm{Cl}_{2}$. The scaling factors are optimized to minize the RMSE in the F38/06 and ZPVE15/06 databases.

Table 24 presents the scaling factors and mean errors for the prediction of harmonic frequencies and zero-point vibrational energies. First of all, Table 24 shows that the scale factors for predicting harmonic frequencies are larger than those for predicting true ZPVEs. Scale factors would be smaller for predicting fundamentals (in fact, based on the work of Scott and Radom [149], we recommend multiplying the ZPVE scale factor by 0.980 if one's goal is to predict
Table 19 MUE (kcal/mol) for the TMAE9/05, MLBE21/05, and 3dTMRE18/06 databases

The TZQ basis set is employed for the TMAE9/05 and MLBE21/05 databases. The QZVP basis set is employed for the 3dTMRE18/06 database

\begin{tabular}{|c|c|c|c|c|c|c|c|}
\hline \multirow[t]{2}{*}{ Method } & \multicolumn{2}{|c|}{ TMAE9/05 } & \multicolumn{2}{|c|}{ MLBE21/05 } & \multicolumn{2}{|c|}{ 3dTMRE18 } & \multirow{2}{*}{$\frac{\text { TMRE48 }}{\text { BMUE }}$} \\
\hline & MSE & MUE & MSE & MUE & MSE & MUE & \\
\hline M06 & -3.1 & 4.7 & -0.6 & 5.4 & -2.1 & 6.6 & 5.6 \\
\hline M06-L & 0.2 & 4.9 & 4.7 & 5.4 & 3.8 & 6.9 & 5.7 \\
\hline M05 & -3.0 & 6.9 & -0.7 & 5.5 & -3.0 & 7.8 & 6.8 \\
\hline B98 & -8.9 & 9.7 & -0.4 & 5.8 & -4.3 & 9.6 & 8.4 \\
\hline BLYP & 4.8 & 5.3 & 9.0 & 9.6 & 5.5 & 10.6 & 8.5 \\
\hline VSXC & 5.5 & 10.2 & 6.3 & 6.6 & 8.2 & 8.9 & 8.6 \\
\hline TPSSh & -11.0 & 11.0 & 2.1 & 5.5 & 1.0 & 9.7 & 8.7 \\
\hline PBE & 3.9 & 7.7 & 11.7 & 12.1 & 10.3 & 10.8 & 10.2 \\
\hline B97-3 & -15.3 & 15.3 & -3.3 & 8.3 & -5.2 & 8.7 & 10.8 \\
\hline B3LYP & -16.7 & 16.7 & -0.6 & 6.0 & -6.6 & 12.0 & 11.6 \\
\hline PBEh & -19.3 & 25.0 & -2.7 & 6.3 & -9.6 & 13.1 & 14.8 \\
\hline BMK & -22.1 & 22.1 & -7.1 & 10.2 & -9.1 & 12.7 & 15.0 \\
\hline M05-2X & -17.8 & 23.3 & -10.8 & 13.5 & -16.4 & 19.6 & 18.8 \\
\hline M06-2X & -20.0 & 22.6 & -11.8 & 13.8 & -17.2 & 21.1 & 19.1 \\
\hline Average (DFT) & -8.8 & 13.2 & -0.3 & 8.1 & -3.2 & 11.3 & 10.9 \\
\hline
\end{tabular}


Table 20 Metal atom excitation energy $(\mathrm{kcal} / \mathrm{mol})^{\mathrm{a}}$

\begin{tabular}{|c|c|c|c|c|c|c|c|}
\hline & $\mathrm{Be}$ & $\mathrm{Mg}$ & Mn & $\mathrm{Cu}^{+}$ & $\mathrm{Pd}$ & MSE & MUE \\
\hline Exp. & 62.84 & 62.47 & 48.76 & 62.70 & 18.77 & & \\
\hline Scalar rel. ${ }^{\mathrm{b}}$ & $-^{\mathrm{c}}$ & $-^{c}$ & $3.92^{\mathrm{d}}$ & $-10.38^{e}$ & $-{ }^{\mathrm{f}}$ & & \\
\hline $\mathrm{S}-\mathrm{O} \mathrm{g}$ & -0.01 & -0.12 & -0.66 & -2.06 & -2.26 & & \\
\hline Total rel. ${ }^{\mathrm{h}}$ & -0.01 & -0.12 & 3.26 & -12.44 & -2.26 & & \\
\hline VSXC & 58.8 & 60.1 & 44.8 & 66.2 & 18.8 & -1.4 & 2.8 \\
\hline B98 & 57.6 & 64.6 & 44.9 & 59.9 & 17.9 & -2.1 & 3.0 \\
\hline M06-L & 53.4 & 60.9 & 46.5 & 68.2 & 21.7 & -3.3 & 4.0 \\
\hline M06 & 57.2 & 63.2 & 55.2 & 61.6 & 31.1 & 2.5 & 5.2 \\
\hline B97-3 & 56.1 & 64.1 & 62.3 & 55.5 & 18.6 & 0.2 & 5.9 \\
\hline B3LYP & 56.6 & 64.1 & 35.2 & 52.4 & 15.2 & -6.4 & 7.1 \\
\hline M06-2X & 63.1 & 69.9 & 62.0 & 48.6 & 22.1 & 2.0 & 7.7 \\
\hline M05 & 64.3 & 67.4 & 57.1 & 71.2 & 34.1 & 7.7 & 7.7 \\
\hline BLYP & 56.8 & 65.5 & 26.0 & 56.5 & 15.8 & -7.0 & 8.2 \\
\hline M05-2X & 66.0 & 75.0 & 66.7 & 56.9 & 21.1 & 6.1 & 8.4 \\
\hline PBEh & 52.7 & 58.0 & 34.9 & 51.3 & 15.0 & -8.7 & 8.7 \\
\hline PBE & 53.1 & 60.1 & 23.1 & 58.7 & 16.6 & -8.8 & 8.8 \\
\hline TPSSh & 55.8 & 58.7 & 26.5 & 54.4 & 14.0 & -9.2 & 9.2 \\
\hline BMK & 53.0 & 61.1 & 45.7 & 42.0 & -7.4 & -12.2 & 12.2 \\
\hline Average & & & & & & -2.9 & 7.1 \\
\hline
\end{tabular}

All calculated excitation energies are for the lowest excited state and include the relativistic contribution

a The aug-cc-pVQZ basis sets are employed for $\mathrm{Be}, \mathrm{Mg}$, and $\mathrm{Cu}$. The basis set for Pd is taken from Quintal. [79] The QZVP [61] basis set is employed for $\mathrm{Mn}$

${ }^{\mathrm{b}}$ Scalar relativistic effect

c Assumed to be negligible

d Taken from Raghavachari and Trucks, Ref. [81]

e Taken from Martin and Hay, Ref. [82]

${ }^{f}$ The effect is taken into account by using a relativistic effective core potential

g Spin-orbit effect

$\mathrm{h}$ This row, which is the sum of the previous two, is the total relativistic effect that has been added to all DFT results to produce the values in the 14 DFT rows of this table

fundamental frequencies). Second, Table 24 shows that the scale factors for methods that are not constrained to have full Hartree-Fock exchange are within $3.6 \%$ of unity and the mean unsigned error in ZPVEs for these methods are all less than or equal to $0.41 \mathrm{kcal} / \mathrm{mol}$ without scaling or $0.16 \mathrm{kcal} /$ mol with scaling.

\section{Concluding remarks}

This paper presents two new hybrid meta-GGA exchangecorrelation functionals, M06 and M06-2X, for thermochemistry, thermochemical kinetics, noncovalent interactions, and excited states. The M06 and M06-2X functionals have been comparatively assessed against 22 main-group ground-state energetic databases and three main-group excited-state energetic databases. The M06 and M06-2X functionals have also been tested against four databases involving transition metals. We also assesses the accuracy using 40 bond lengths, 38 vibrational frequencies, and 15 vibrational zero-point energies, for a total of 496 data. Of these 496 data, 182 were not used during parametrization.

From the assessment, we make the following recommendations:

(1) The M06-2X, BMK, and M05-2X functionals are recommended most highly for the study of main-group thermochemistry and kinetics; they have smallest BMUE for the combined TK253 database (see Table 12) and also for the separate TC177 and DBH76 databases (see Table 12)

(2) M06-2X, M05-2X, and M06 are the best functionals for a combination of main-group thermochemistry, kinetics, and noncovalent interactions; they have the smallest BMUE for the TKNC306 database (see Table 18).

(3) M06-HF is the best functional for the study of longrange charge transfer via a TDDFT approach (see the CTE3 database in Table 17). 
Table 21 Overall assessment

\begin{tabular}{|c|c|c|c|}
\hline \multirow[t]{2}{*}{ Method } & \multirow{2}{*}{$\frac{\text { MGE350 }}{\text { WMUE (reduced units) }}$} & \multirow{2}{*}{$\frac{\text { TME53 }^{\mathrm{a}}}{\text { BMUE }(\mathrm{kcal} / \mathrm{mol})}$} & \multirow{2}{*}{$\frac{\text { M06E403 }^{\mathrm{b}}}{\text { WMUE }^{\mathrm{b}} \text { (reduced units) }}$} \\
\hline & & & \\
\hline M06 & 0.67 & 5.50 & 0.62 \\
\hline M05 & 0.75 & 7.00 & 0.74 \\
\hline M06-L & 0.96 & 5.27 & 0.76 \\
\hline B98 & 0.90 & 7.03 & 0.82 \\
\hline B97-3 & 0.80 & 9.53 & 0.89 \\
\hline M06-2X & 0.39 & 16.28 & 1.02 \\
\hline BMK & 0.58 & 14.33 & 1.02 \\
\hline M05-2X & 0.46 & 16.18 & 1.05 \\
\hline VSXC & 1.40 & 7.12 & 1.08 \\
\hline TPSSh & 1.28 & 8.85 & 1.10 \\
\hline B3LYP & 1.13 & 10.44 & 1.10 \\
\hline PBEh & 0.91 & 13.30 & 1.14 \\
\hline BLYP & 1.73 & 8.42 & 1.31 \\
\hline PBE & 1.66 & 9.87 & 1.35 \\
\hline M06-HF & 0.48 & - & - \\
\hline HFLYP & 1.90 & - & - \\
\hline $\mathrm{HF}$ & 4.35 & - & - \\
\hline Average (14 DFTs) & 0.97 & 9.94 & 1.00 \\
\hline Average (16 DFTs) & 1.00 & & \\
\hline Average (all) & 1.20 & - & - \\
\hline
\end{tabular}

Table 22 Mean errors for bond lengths $(\AA)$

\begin{tabular}{|c|c|c|c|c|c|c|c|c|c|}
\hline \multirow[t]{2}{*}{ Method } & \multicolumn{2}{|c|}{ MGBL19 } & \multicolumn{2}{|c|}{ MLBL13 } & \multicolumn{2}{|c|}{ TMBL8 } & \multirow{2}{*}{$\frac{\text { TMBL7 }}{\text { MUE }^{\mathrm{a}}}$} & \multirow[t]{2}{*}{ BMUE39 ${ }^{\mathrm{b}}$} & \multirow[t]{2}{*}{ BMUE40 } \\
\hline & MSE & MUE & MSE & MUE & MSE & MUE & & & \\
\hline PBE & 0.009 & 0.009 & -0.002 & 0.010 & 0.016 & 0.031 & 0.029 & 0.016 & 0.017 \\
\hline TPSSh & 0.002 & 0.004 & -0.004 & 0.010 & 0.019 & 0.049 & 0.047 & 0.020 & 0.021 \\
\hline BLYP & 0.012 & 0.012 & 0.007 & 0.013 & 0.034 & 0.039 & 0.041 & 0.022 & 0.022 \\
\hline M06-L & -0.001 & 0.003 & -0.001 & 0.011 & 0.101 & 0.118 & 0.043 & 0.019 & 0.044 \\
\hline VSXC & 0.003 & 0.003 & 0.008 & 0.013 & 0.119 & 0.138 & 0.037 & 0.018 & 0.052 \\
\hline M06 & -0.005 & 0.007 & -0.007 & 0.018 & 0.112 & 0.131 & 0.056 & 0.027 & 0.052 \\
\hline B3LYP & 0.000 & 0.005 & -0.003 & 0.010 & 0.126 & 0.154 & 0.057 & 0.024 & 0.057 \\
\hline M05 & -0.005 & 0.007 & -0.001 & 0.021 & 0.134 & 0.154 & 0.071 & 0.033 & 0.061 \\
\hline B98 & -0.001 & 0.005 & 0.001 & 0.011 & 0.156 & 0.174 & 0.086 & 0.034 & 0.063 \\
\hline PBEh & -0.004 & 0.006 & -0.010 & 0.014 & 0.129 & 0.173 & 0.061 & 0.027 & 0.064 \\
\hline BMK & -0.004 & 0.007 & -0.011 & 0.025 & 0.161 & 0.183 & 0.075 & 0.036 & 0.072 \\
\hline B97-3 & -0.004 & 0.006 & 0.009 & 0.018 & 0.175 & 0.197 & 0.095 & 0.040 & 0.074 \\
\hline M05-2X & -0.008 & 0.009 & 0.005 & 0.023 & 0.174 & 0.213 & 0.113 & 0.048 & 0.082 \\
\hline M06-2X & -0.006 & 0.007 & 0.006 & 0.037 & 0.202 & 0.244 & 0.143 & 0.062 & 0.096 \\
\hline M06-HF & -0.011 & 0.012 & & & & & & & \\
\hline HFLYP & -0.033 & 0.033 & & & & & & & \\
\hline $\mathrm{HF}$ & -0.022 & 0.035 & & & & & & & \\
\hline Average (DFT) & -0.003 & 0.008 & 0.000 & 0.017 & 0.118 & 0.143 & 0.068 & 0.030 & 0.055 \\
\hline Average (all) & -0.005 & 0.010 & & & & & & & \\
\hline
\end{tabular}

The MG3S basis set is employed for the MGBL19 database, and the TZQ basis set is employed for the MLBL13 and TMBL databases

${ }^{a}$ This MUE excludes the bond length of $\mathrm{Cr}_{2}$

${ }^{\mathrm{b}}$ BMUE39 $=(\operatorname{MUE}($ MGBL19) + MUE(MLBL13) + MUE(TMBL7) $) / 3$

${ }^{c}$ BMUE40 $=($ MUE $($ MGBL19) + MUE $($ MLBL13 $)+\operatorname{MUE}($ TMBL8) $) / 3$ 
Table 23 Vibrational data $\left(\mathrm{cm}^{-1}\right)$ for $\mathrm{OH}$ and $\mathrm{Cl}_{2}$ in the $\mathrm{F} 38 / 06$ and ZPVE15/06 databases

\begin{tabular}{lll}
\hline Molecules & $\mathrm{OH}$ & $\mathrm{Cl}_{2}$ \\
\hline Harmonic frequency & 3737.8 & 559.7 \\
ZPVE & 1847.7 & 279.2 \\
\hline
\end{tabular}

$\omega_{e}$ and $\omega_{\mathrm{e}} x_{\mathrm{e}}$ for $\mathrm{OH}$ and $\mathrm{Cl}_{2}$ are taken from NIST Webbook [152]

(4) The M06-L, M06, and M05 functionals are the best functionals for the study of organometallic and inorganometallic thermochemistry; they have smallest BMUE for the TME53 and M06E403 databases (see Table 21).

(5) The M06-2X, M05-2X, M06-HF, and M06 functionals are the best functionals for the study of noncovalent interactions; they have the smallest BMUEs for the NCIE53 database (see Table 12).

(6) When the use of full Hartree-Fock exchange is important, for example to avoid the error of self-interaction at long-range, the M06-HF functional can be recommended since it has reasonably good overall performance (excluding transition metals) even though it has full Hartree-Fock exchange.

(7) When a local functional is required for efficiency sake or because of program requirements, the M06-L functional can be recommended because it has reasonably good overall performance even though it has the locality constraint. In addition, M06-L is the best functional for transition metal energetics (TME53 database, see Table 21)

Acknowledgments The authors are grateful to Nathan Schultz for helpful discussions. This work was supported in part by the US Department of Energy, Office of Basic Energy Sciences under grant number DE-FG02-86ER13579 (kinetics), by the National Science Foundation under grant numbers CHE03-49122 (complex systems) and ITR0428774 (planetary ice), and by the Office of Naval Research under award number N00014-05-0538 (tools and software).

\section{Appendix: Acronyms}

All acronyms that are not included in Tables 1 and 3 are explained in Table 25.

Table 24 Scaling factors for the predictions of harmonic frequencies and zero-point vibrational energies

\begin{tabular}{|c|c|c|c|c|c|c|c|c|}
\hline \multirow[t]{3}{*}{ Method } & \multicolumn{3}{|c|}{ Frequencies $\left(\mathrm{cm}^{-1}\right)$} & \multicolumn{3}{|c|}{ Zero-point energies $(\mathrm{kcal} / \mathrm{mol})$} & \multicolumn{2}{|c|}{$\operatorname{BMUE}^{\mathrm{a}}(\mathrm{kcal} / \mathrm{mol})$} \\
\hline & \multirow[t]{2}{*}{ Scaling factor } & \multicolumn{2}{|l|}{ MUE } & \multirow[t]{2}{*}{ Scaling factor } & \multicolumn{2}{|l|}{ MUE } & \multirow[b]{2}{*}{ No scaling } & \multirow[b]{2}{*}{ Scaling } \\
\hline & & No scaling & Scaling & & No scaling & Scaling & & \\
\hline VSXC & 1.001 & 24 & 24 & 0.989 & 0.13 & 0.08 & 0.10 & 0.07 \\
\hline PBE & 1.025 & 56 & 29 & 1.012 & 0.13 & 0.08 & 0.15 & 0.08 \\
\hline B98 & 0.995 & 32 & 30 & 0.984 & 0.19 & 0.08 & 0.14 & 0.08 \\
\hline TPSSh & 1.002 & 28 & 28 & 0.986 & 0.15 & 0.09 & 0.11 & 0.08 \\
\hline BLYP & 1.031 & 67 & 25 & 1.016 & 0.17 & 0.09 & 0.18 & 0.08 \\
\hline B3LYP & 0.998 & 31 & 31 & 0.985 & 0.17 & 0.08 & 0.13 & 0.09 \\
\hline B97-3 & 0.986 & 46 & 34 & 0.974 & 0.29 & 0.09 & 0.21 & 0.09 \\
\hline M06-L & 0.996 & 39 & 36 & 0.980 & 0.21 & 0.10 & 0.16 & 0.10 \\
\hline BMK & 0.984 & 52 & 42 & 0.973 & 0.32 & 0.09 & 0.23 & 0.11 \\
\hline PBEh & 0.989 & 46 & 39 & 0.978 & 0.27 & 0.10 & 0.20 & 0.11 \\
\hline M05 & 0.989 & 54 & 49 & 0.979 & 0.26 & 0.12 & 0.21 & 0.13 \\
\hline M05-2X & 0.975 & 72 & 45 & 0.964 & 0.41 & 0.13 & 0.31 & 0.13 \\
\hline M06-2X & 0.982 & 57 & 47 & 0.972 & 0.34 & 0.13 & 0.25 & 0.13 \\
\hline M06 & 0.994 & 60 & 59 & 0.983 & 0.23 & 0.16 & 0.20 & 0.16 \\
\hline $\mathrm{HF}$ & 0.932 & 180 & 69 & 0.921 & 0.93 & 0.20 & 0.72 & 0.20 \\
\hline M06-HF & 0.967 & 95 & 68 & 0.957 & 0.49 & 0.22 & 0.38 & 0.20 \\
\hline HFLYP & 0.912 & 233 & 74 & 0.902 & 1.17 & 0.22 & 0.92 & 0.21 \\
\hline Average (DFT) & & 67 & 41 & & 0.34 & 0.12 & 0.26 & 0.12 \\
\hline Average (all) & & 69 & 43 & & 0.35 & 0.12 & 0.27 & 0.12 \\
\hline
\end{tabular}

The MG3S basis set is employed for all calculations in this table

${ }^{\mathrm{a}} \mathrm{BMUE}=(\operatorname{MUE}(\mathrm{F} 38 / 06$, in $\left.\mathrm{kcal} / \mathrm{mol}))+\operatorname{MUE}(\mathrm{ZPVE} 15 / 06)\right) / 2$. Note that $1 \mathrm{kcal} / \mathrm{mol}=349.75 \mathrm{~cm}^{-1}$ 
Table 25 Acronyms, excluding those in Tables 1 and 3

\begin{tabular}{|c|c|}
\hline Acronym & Meaning \\
\hline $\mathrm{AE}$ & Atomization energy \\
\hline AMUE & Average mean unsigned error \\
\hline aug-cc-pVTZ & Augmented correlation-consistent polarized valence-triple-zeta (basis set) \\
\hline AVQZ & Augmented valence quadruple zeta (basis set) \\
\hline $\mathrm{BH}$ & Barrier heights \\
\hline BMUE & Balanced mean unsigned error \\
\hline BSSE & Basis set superposition error \\
\hline $\mathrm{cp}$ & Counterpoise correction \\
\hline $\mathrm{CT}$ & Charge transfer \\
\hline DFT & Density functional theory \\
\hline EA & Electron affinity \\
\hline ES & Electronic spectroscopy (sometimes called “UV-Vis" spectroscopy) \\
\hline GGA & Generalized gradient approximation \\
\hline $\mathrm{HF}$ & Hartree-Fock \\
\hline IP & Ionization potential \\
\hline LSDA & Local spin density approximation \\
\hline MC-QCISD & Multi-coefficient QCISD method \\
\hline MG & Main group \\
\hline MG3 & Modified Gaussian3Large (basis set) \\
\hline MG3S & MG3-semidiffuse (basis set) \\
\hline MMUE & Mean mean unsigned error \\
\hline MQZVP & The modified QZVP basis set \\
\hline MP2 & M $\phi 1$ ler-Plesset 2nd-order (perturbation theory) \\
\hline MSE & Mean signed error \\
\hline MUE & Mean unsigned error \\
\hline MUEPB & MUE per bond \\
\hline No-cp & Without counterpoise correction \\
\hline PA & Proton affinity \\
\hline pVTZ & Polarized valence triple zeta (basis set) \\
\hline QCISD & Quadratic configuration interaction with single and double excitations \\
\hline QZVP & Quadruple-zeta-valence polarized (basis set) \\
\hline RMSE & Root mean square error \\
\hline TC & (Main-group) thermochemistry \\
\hline $\mathrm{TD}$ & Time-dependent \\
\hline TDDFT & Time-dependent DFT \\
\hline $\mathrm{TM}$ & Transition metal bonding \\
\hline TZQ & Triple-zeta quality (basis set) \\
\hline UEG & Uniform electron gas \\
\hline WMUE & Weighted mean unsigned eror \\
\hline ZPVE & Zero-point vibrational energy \\
\hline
\end{tabular}

\section{References}

1. Boese AD, Handy NC (2002) J Chem Phys 116:9559

2. Tao J, Perdew JP, Staroverov VN, Scuseria GE (2003) Phys Rev Lett 91:146401

3. Staroverov VN, Scuseria GE, Tao J, Perdew JP (2003) J Chem Phys 119:12129

4. Zhao Y, Lynch BJ, Truhlar DG (2004) J Phys Chem A 108:2715
5. Boese AD, Martin JML (2004) J Chem Phys 121:3405

6. Zhao Y, Truhlar DG (2004) J Phys Chem A 108:6908

7. Xu X, Goddard WA (2004) Proc Natl Acad Sci USA 101:2673

8. Zhao Y, Lynch BJ, Truhlar DG (2005) Phys Chem Chem Phys 7:43

9. Perdew JP, Ruzsinszky A, Tao J, Staroverov VN, Scuseria GE, Csonka GI (2005) J Chem Phys 123:62201

10. Zhao Y, Truhlar DG (2005) J Phys Chem A 109:5656 
11. Keal TW, Tozer DJ (2005) J Chem Phys 123:121103

12. Zhao Y, Schultz NE, Truhlar DG (2005) J Chem Phys 123:161103

13. Becke AD (2005) J Chem Phys 122:64101

14. Zhao Y, Schultz NE, Truhlar DG (2006) J Chem Theory Comput 2:364

15. Mori-Sanchez P, Cohen AJ, Yang W (2006) J Chem Phys 124:91102

16. Zhao Y, Truhlar DG (2006) J Chem Phys 125:194101

17. Grimme S (2006) J Chem Phys 124:034108

18. Grimme S (2006) J Comp Chem 27:1787

19. Zhao Y, Truhlar DG (2006) J Phys Chem A 110:13126

20. Scuseria GE, Staroverov VN (2005) . In: Dykstra CE, Frenking G, Kim KS, Scuseria GE (eds) Theory and application of computational chemistry: the first 40 years. Elsevier, Amsterdam, pp 669-724

21. Voorhis TV, Scuseria GE (1998) J Chem Phys 109:400

22. Becke AD (1998) J Chem Phys 109:2092

23. Baerends EJ, Ellis DE, Ros P (1973) Chem Phys 2:41

24. Dunlap BI, Connolly JWD, Sabin JR (1979) J Chem Phys 71:3396

25. Vahtras O, Almlöf J, Feyereisen MW (1993) Chem Phys Lett 213:514

26. Kendall RA, Apra E, Bernholdt DE, Bylaska EJ, Dupuis M, Fann GI, Harrison RJ, Ju J, Nichols JA, Nieplocha J, Straatsma TP, Windus TL, Wong AT (2000) Comput Phys Commun 128:260

27. Te Velde G, Bickelhaupt FM, Baerends EJ, Fonseca Guerra C, Van Gisbergen SJA, Snijders JG, Ziegler T (2001) J Comp Chem 22:931

28. VandeVondele J, Krack M, Mohamed F, Parrinello M, Chassaing T, Hutter J (2005) Comput Phys Commun 167:103

29. Jung Y, Sodt A, Gill PMW, Head-Gordon M (2005) Proc Natl Acad Sci USA 102:6692

30. Eichkorn K, Treutler O, Oehm H, Haeser M, Ahlrichs R (1995) Chem Phys Lett 240:283

31. Eichkorn K, Weigend F, Treutler O, Ahlrichs R (1997) Theo Chem Acc 97:119

32. Füsti-Molnár L, Pulay P (2003) Theochem 25: 666-667

33. Skylaris C-K, Haynes PD, Mostofi AA, Payne MC (2006) Phys Status Solidi B, Basic Res 243:973

34. Dreuw A, Head-Gordon M (2006) Chem Rev 105:4009

35. Zhao Y, Truhlar DG (2006) Org Lett 8:5753

36. Lynch BJ, Fast PL, Harris M, Truhlar DG (2000) J Phys Chem A $104: 4811$

37. Zhao Y, Truhlar DG (2005) J Chem Theory Comput 1:415

38. Schultz N, Zhao Y, Truhlar DG (2005) J Phys Chem A 109:4388

39. Schultz N, Zhao Y, Truhlar DG (2005) J Phys Chem A 109: 11127

40. Zhao Y, Truhlar DG (2006) J Phys Chem A 110:10478

41. Zhao Y, Truhlar DG (2006) J Chem Theory Comput 2:1009

42. Zhao Y, Truhlar DG (2006) J Phys Chem A 110:5121

43. Zhao Y, Truhlar DG (2006) J Chem Phys 124:224105

44. Zhao Y, Truhlar DG (2007) J Chem Theory Comput 3:289

45. Zhang Y, Li ZH, Truhlar DG (2007) J Chem Theory Comput 3:593

46. Kabelác M, Sherer EC, Cramer CJ, Hobza P (2006) Chem Eur J 13:2067

47. Schultz NE, Gherman BF, Cramer CJ, Truhlar DG (2006) J Phys Chem B 110:24030

48. Zhao Y, Truhlar DG (2007) J Org Chem 72:295

49. Zhao Y, Lynch BJ, Truhlar DG (2004) J Phys Chem A 108:4786

50. Zhao Y, González-García N, Truhlar DG (2005) J Phys Chem A 109:2012

51. Chakravorty SJ, Gwaltney SR, Davidson ER, Parpia FA, Fischer CFF (1993) Phys Rev A 47:3649

52. Lynch BJ, Zhao Y, Truhlar DG (2003) J Phys Chem A 107:1384
53. Zheng JJ, Zhao Y, Truhlar DG (2007) J Chem Theory Comput 3:569

54. Pople JA, Head-Gordon M, Raghavachari K (1987) J Chem Phys 87:5968

55. Fast PL, Sanchez ML, Truhlar DG (1999) Chem Phys Lett 306:407

56. Curtiss LA, Redfern PC, Raghavachari K, Rassolov V, Pople JA (1999) J Chem Phys 110:4703

57. Curtiss LA, Raghavachari K, Redfern PC, Rassolov V, Pople JA (1998) J Chem Phys 109:7764

58. Frisch MJ, Pople JA, Binkley JS (1984) J Chem Phys 80:3265

59. Hehre WJ, Radom L, Schleyer PvR, Pople JA (1986) Ab initio molecular orbital theory, 1st ed., Wiley, New York

60. Izgorodina EI, Coote ML, Radom L (2005) J Phys Chem A 109:7558

61. Weigend F, Furche F, Ahlrichs R (2003) J Chem Phys 119:12753

62. Fast PL, Truhlar DG (2000) J Phys Chem A 104:6111

63. Lynch BJ, Truhlar DG (2003) J Phys Chem A 107:3898

64. Sinnokrot MO, Sherrill CD (2004) J Phys Chem A 108:10200

65. Jurecka P, Sponer J, Cerny J, Hobza P (2006) Phys Chem Chem Phys 8:1985

66. Runge E, Gross EKU (1984) Phys Rev Lett 52:997

67. Casida ME (1996) . In: Seminario JM (ed) Recent developments and applications of modern density functional theory. Elsevier, Amsterdam, p 391

68. Bauernschmitt R, Ahlrichs R (1996) Chem Phys Lett 256:454

69. Stratmann RE, Scuseria GE, Frisch MJ (1998) J Chem Phys 109:8218

70. Marques MAL, Gross EKU (2004) Annu Rev Phys Chem 55:427

71. Furche F, Rappoport D (2005) Comp Theor Chem 16:93

72. Sadlej AJ (1991) Theor Chim Acta 79:123

73. Casida ME, Jamorski C, Casida KC, Salahub DR (1998) J Chem Phys 108:4439

74. Hamprecht FA, Cohen AJ, Tozer DJ, Handy NC (1998) J Chem Phys 109:6264

75. NIST Computational Chemistry Comparison and Benchmark DataBase, http://srdata.nist.gov/cccbdb/

76. Furche F, Perdew JP (2006) J Chem Phys 124:044103

77. Woon DE, T.H. Dunning J (1993) J Chem Phys 98:1358

78. Balabanov NB, Peterson KA (2005) J Chem Phys 123:064107

79. Quintal MM, Karton A, Iron MA, Boese AD, Martin JML (2006) J Phys Chem A 110:709

80. Truhlar DG, Lynch BJ, Zhao Y, http://comp.chem.umn.edu/ basissets/basis.cgi

81. Raghavachari K, Trucks GW (1989) J Chem Phys 91:1062

82. Martin RL, Hay PJ (1981) J Chem Phys 75:4539

83. Boys SF, Bernardi F (1970) Mol Phys 19:553

84. Schwenke DW, Truhlar DG (1985) J Chem Phys 82:2418

85. Frisch MJ, Trucks GW, Schlegel HB, Scuseria GE, Robb MA, Cheeseman JR, Montgomery JA, Jr., Kudin KN, Burant JC, Millam JM, Iyengar SS, Tomasi J, Barone V, Mennucci B, Cossi M, Scalmani G, Rega N, Petersson GA, Nakatsuji H, Hada M, Ehara M, Toyota K, Fukuda R, Hasegawa J, Ishida M, Nakajima T, Honda Y, Kitao O, Nakai H, Klene M, Li X, Knox JE, Hratchian HP, Cross JB, Adamo C, Jaramillo J, Gomperts R, Stratmann RE, Yazyev O, Austin AJ, Cammi R, Pomelli C, Ochterski JW, Ayala PY, Morokuma K, Voth GA, Salvador P, Dannenberg JJ, Zakrzewski G, Dapprich S, Daniels AD, Strain MC, Farkas O, Malick DK, Rabuck AD, Raghavachari K, Foresman JB, Ortiz JV, Cui Q, Baboul AG, Clifford S, Cioslowski J, Stefanov BB, Liu G, Liashenko A, Piskorz P, Komaromi I, Martin RL, Fox DJ, Keith T, Al-Laham MA, Peng CY, Nanayakkara A, Challacombe M, Gill PMW, Johnson B, Chen W, Wong MW, Gonzalez C, Pople JA. (2003) . Gaussian Inc., Pittsburgh

86. Voorhis TV, Scuseria GE (1997) Mol Phys 92:601

87. Perdew JP, Burke K, Ernzerhof M (1996) Phys Rev Lett 77:3865 
88. Becke AD (1986) J Chem Phys 84:4524

89. Kohn W, Sham LJ (1965) Phys Rev 140:1133

90. Stoll H, Pavkidou CME, Preuss H (1978) Theor Chim Acta 49:143

91. Becke AD (1988) Phys Rev A 38:3098

92. Lee C, Yang W, Parr RG (1988) Phys Rev B 37:785

93. Becke AD (1993) J Chem Phys 98:5648

94. Stephens PJ, Devlin FJ, Chabalowski CF, Frisch MJ (1994) J Phys Chem 98:11623

95. Schmider HL, Becke AD (1998) J Chem Phys 108:9624

96. Adamo C, Barone V (1999) J Chem Phys 110:6158

97. Valentin CD, Pacchioni G, Bredow T, Dominguez-Ariza D, Illas F (2002) J Chem Phys 117:2299

98. Wilson PJ, Bradley TJ, Tozer DJ (2001) J Chem Phys 115:9233

99. Curtiss LA, Redfern PC, Raghavachari K (2005) J Chem Phys 123:124107

100. Perdew JP, Schmidt K (2001) In: Van-Doren V, Alsenoy CV, Geerlings P (eds) Density functional theory and its applications to materials. American Institute of Physics, New York, p 1

101. Zhao Y, Pu J, Lynch BJ, Truhlar DG (2004) Phys Chem Chem Phys 6:673

102. Woodcock HL, Schaefer HF, Schreiner PR (2002) J Phys Chem A $106: 11923$

103. Champagne B, Perpete EA, van Gisbergen SJA, Baerends E-J, Snijders JG, Soubra-Ghaoui C, Robins KA, Kirtman B (1998) J Chem Phys 109:10489

104. Champagne B, Perpete EA, Jacquemin D, Gisbergen SJAV, Baerends E-J, Soubra-Ghaoui C, Robins KA, Kirtman B (2000) J Phys Chem A 104:4755

105. Schreiner PR, Fokin AA, Pascal RA Jr, de Meijere A (2006) Org Lett 8:3635

106. Grimme S (2006) Angew Chem Int Ed 45:4460

107. Phillips JA, Cramer CJ (2005) J Chem Theory Comput 1:827

108. Füsti-Molnár L, Szalay PG (1996) J Phys Chem 100:6288

109. Leininger ML, Schaefer HF (1997) J Chem Phys 107:9059

110. Ljubic I, Sabljic A (2002) J Phys Chem A 106:4745

111. Feller D, Peterson KA (1999) J Chem Phys 110:8384

112. Curtiss LA, Raghavachari K, Redfern PC, Pople JA (2000) J Chem Phys 112:7374

113. Grimme S (2005) J Phys Chem A 109:3067

114. Cioslowski J, Schimeczek M, Liu G, Stoyanov V (2000) J Chem Phys 113:9377

115. Ruiz E, Salahub DR, Vela A (1995) J Am Chem Soc 117:1141

116. Ruiz E, Salahub DR, Vela A (1996) J Phys Chem 100:12265

117. Kool ET, Morales JC, Guckian KM (2000) Angew Chem Int Ed 39:990

118. Barthelemy P, Lee SJ, Grinstaff M (2005) Pure Appl Chem 77:2133

119. Vondrásek J, Bendová L, Klusák V, Hobza P (2005) J Am Chem Soc 127:2615
120. Mansikkamaeki H, Nissinen M, Rissanen K (2004) Angew Chem Int Ed 43:1243

121. Vázquez M, Bermejo MR, Licchelli M, González-Noya AM, Pedrido RM, Sangregorio C, Sorace L, García-Deibe AM, Sanmartín J (2005) Eur J Inorg Chem 17:3479

122. Hobza P, Sponer J (1999) Chem Rev 99:3247

123. Sponer J, Leszczynski J, Hobza P (2001) Biopolymers 61:3

124. Birks JB (1970) Photophysics of aromatic molecules. Wiley, New York, p 71

125. Tawada Y, Tsuneda T, Yanagisawa S, Yanai T, Hirao K (2004) J Chem Phys 120:8425

126. Ben-Shlomo SB, Kaldor U (1990) J Chem Phys 92:3680

127. Nielsen ES, Jorgensen P, Oddershede J (1980) J Chem Phys 73:6238

128. Clouthier DJ, Ramsay DA (1983) Annu Rev Phys Chem 34:31

129. Biermann D, Schmidt W (1980) J Am Chem Soc 102:3163

130. Grimme S, Parac M (2003) Chem Phys Chem 4:292

131. Hautman J, Klein ML (1991) NATO ASI Ser E 205:395

132. Karlin KD (1993) Science 261:701

133. Crabtree RH (1994) The organometallic chemistry of the transition metals, 2nd ed. Wiley, New York

134. George SM (1995) Chem Rev 95:475

135. Somorjai GA (1995) Chem Rev 96:1223

136. Ratner MA, Davis B, Kemp M, Mujica V, Roitberg A, Yalirakil S (1998) Ann N Y Acad Sci 852:22

137. Truhlar DG, Morokuma K (1999) In: ACS symposium series 721 :transition state modeling for catalysis. American Chemical Society, Washington, DC

138. Davidson ER (2000) Chem Rev 100:351

139. Siegbahn PEM, Blomberg MRA (2000) Chem Rev 100:421

140. Gladysz JA (2000) Chem Rev 100:1167

141. Rappe AK, Skiff WM, Casewit CJ (2000) Chem Rev 100:1435

142. Lovelll T, Stranger R, McGrady JE (2001) Inorg chem, 40:39

143. Bertini I, Sigel A, Sigel H (2001) Handbook on Metalloproteins. Marcel Dekker, New York

144. Coperat C, Chabonas M, Saint-Arromon RP, Basset J-M (2003) Angew Chem Int Ed 42:156

145. Cavigliasso G, Stranger R (2005) Inorg Chem 44:5081

146. Carreón-Macedo J-L, Harvey JN (2006) Phys Chem Chem Phys 8:93

147. Tuma C, Sauer J (2006) Phys Chem Chem Phys 8:3955

148. Pople JA, Scott AP, Wong MW (1993) Israel J Chem 33:345

149. Scott AP, Radom L (1996) J Phys Chem 100:16502

150. Fast PL, Corchado J, Sanchez ML, Truhlar DG (1999) J Phys Chem A 103:3139

151. Herzberg G (1966) Molecular spectra and molecular structure. III.Electronic spectra and electronic structure of polyatomic molecules. Van Nostrand Reinhold, New York

152. NIST Chemistry Webbook, http://webbook.nist.gov/chemistry 